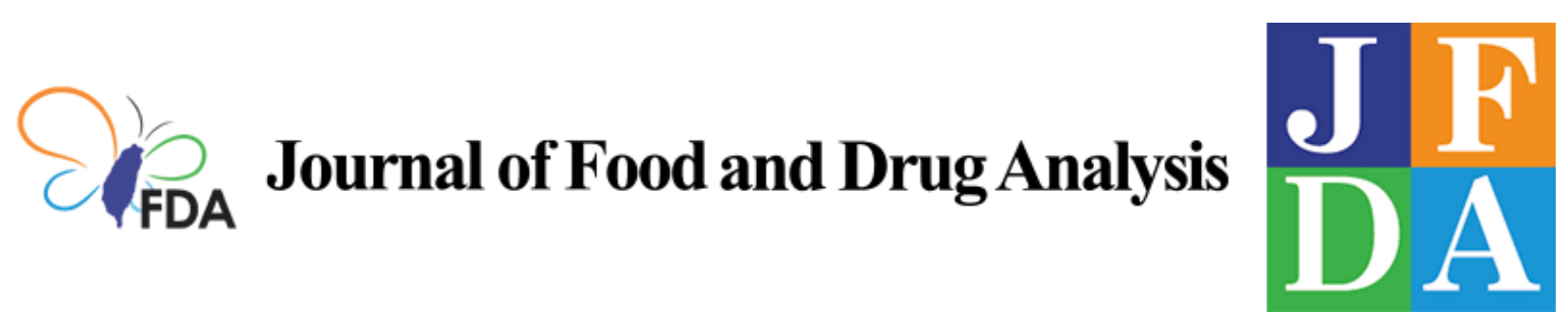

Volume 28 | Issue 4

Article 12

2020

\title{
The analytical and biomedical applications of carbon dots and their future theranostic potential: A review
}

Follow this and additional works at: https://www.jfda-online.com/journal

Part of the Food Science Commons, Materials Chemistry Commons, Medicinal Chemistry and Pharmaceutics Commons, Pharmacology Commons, and the Toxicology Commons (c) (i) (9)

This work is licensed under a Creative Commons Attribution-Noncommercial-No Derivative Works 4.0 License.

\section{Recommended Citation}

Ross, Sukunya; Wu, Ren-Siang; Wei, Shih-Chun; Ross, Gareth M.; and Chang, Huan-Tsung (2020) "The analytical and biomedical applications of carbon dots and their future theranostic potential: A review," Journal of Food and Drug Analysis: Vol. 28 : Iss. 4 , Article 12.

Available at: https://doi.org/10.38212/2224-6614.1154

This Review Article is brought to you for free and open access by Journal of Food and Drug Analysis. It has been accepted for inclusion in Journal of Food and Drug Analysis by an authorized editor of Journal of Food and Drug Analysis. 


\section{The analytical and biomedical applications of carbon dots and their future theranostic potential: A review}

\section{Cover Page Footnote}

We are grateful to the Ministry of Science and Technology (MOST) of Taiwan for providing financial support for this study under contracts 107-2113-M-002-015-MY3, 108-2622-M-002-002-CC2, and 108-2638-M-002-001-MY2. 


\title{
The analytical and biomedical applications of carbon dots and their future theranostic potential: A review
}

\author{
Sukunya Ross ${ }^{a}$, Ren-Siang Wu ${ }^{b}$, Shih-Chun Wei ${ }^{b}$, \\ Gareth M. Ross ${ }^{a}, *$, Huan-Tsung Chang ${ }^{b, c, * *}$ \\ ${ }^{\text {a }}$ Department of Chemistry, Naresuan University, Phitsanulok, 65000, Thailand \\ ${ }^{\mathrm{b}}$ Department of Chemistry, National Taiwan University, Taipei, 10617, Taiwan \\ ${ }^{\mathrm{c}}$ Department of Chemistry, Chung Yuan Christian University, Taoyuan City, 32023, Taiwan
}

\begin{abstract}
In recent years, carbon dots (C-dots) have gained appreciable interest owing to their unique optical properties, including tunable fluorescence, stability against photobleaching and photoblinking, and strong fluorescence. Simple and low-cost hydrothermal and electrochemical approaches have been widely used in the preparation of biocompatible and high-quality C-dots. Various C-dots have been used for the quantitation of small analytes, mostly based on analyte induced fluorescence quenching. Depending on the nature of precursors, synthetic conditions (such as reaction temperature and time), and surface conjugation, multi-function C-dots can be prepared and used in diagnostics and therapeutics. Their strong fluorescence and photostability, enables use in cell imaging. Their biological activity from the surface residues and capability of generating reactive oxygen species, have allowed many $\mathrm{C}$-dots to become candidates as antibacterial and anticancer reagents. After suitable conjugation, biocompatible and fluorescent C-dots can be used for diagnostics and therapeutics, thus, showing their great potential in the area of theranostics.
\end{abstract}

Keywords: Carbon dots, Analytical, Diagnostic, Therapeutic, Theranostics

\section{Introduction}

C arbon dots (C-dots; CDs) recently emerged as a new type of zero-dimensional fluorescent carbon nanostructures. C-dots were discovered by $\mathrm{Xu}$ et al. during purification of singlewalled carbon nanotubes (SWCNTs) using gel electrophoresis in 2004 [1]. Owing to their unique and exceptional properties, $\mathrm{C}$-dots have attracted appreciable research interest $[2,3]$. These properties arise from their inherent structural features such as low toxicity, biocompatibility and permeability, weak interactions with proteins, resistance to swelling and photobleaching, easy clearance from the body, low cost, and immune system evasion [4]. To exploit the unique properties of C-dots and their low cost and ease of synthesis, much work has been done in areas such as optical sensing [5, 6], bioimaging [7], photocatalysis [8-11] and electrocatalysis [12-14]. Interestingly, imaging agents have played an essential role as a platform for real-time multimodal imaging-associated cancer therapy [15-17]. These important features make them an exceptional vehicle for fluorescence labeling and imaging and thus make them a solid base for diagnostics. Imaging modalities enable visualization of different in vivo phenomena like biodistribution of therapeutic systems. In terms of therapeutics, there are significant factors affecting the design of targeted drug delivery systems, including the efficient means of delivery, conservation of drug bioactivity, uptake of drug delivery systems within cells, release of therapeutic

Received 30 May 2020; Revised 7 September 2020; Accepted 18 September 2020.

Available online 1 December 2020

* Corresponding author at: Department of Chemistry, Naresuan University, Phitsanulok, 65000, Thailand.

** Corresponding author at: Department of Chemistry, National Taiwan University, Taipei, 10617, Taiwan.

E-mail addresses: gareth@nu.ac.th (G.M. Ross), changht@ntu.edu.tw (H.-T. Chang). 
payloads from the system in target tissue/area and monitoring of therapeutic efficacy $[18,19]$.

Over the last few years, biomedical research has gradually become more focused on the transformation of conventional treatment procedures into a more personalized treatment modality. One of the areas of focus is the combined therapeutic and diagnostic platforms in the form of theranostic agents. The theranostic approach of integrating diagnostic and therapeutic approaches in one entity has and continues to receive considerable attention as a promising alternative to invasive and nonspecific treatments, for example in cancer treatment $[20,21]$. The objectives of theranostic approaches is to achieve faster, highly sensitive and precise diagnostic and therapeutic systems $[22,23]$. Theranostics is a treatment that amalgamates multiple disciplines such as pharmacogenomics, imaging, therapy and targeting. Theranostics makes the monitoring of therapeutic efficacy possible and helps to improve therapeutic outcomes thus helping avoid undesirable side effects [24]. Theranostic systems can be a beneficial aid to physicians to make well informed decisions regarding medicine dose adjustment, augmentation of delivery routes or discontinuation of treatment paving way for the development of personalized medicine as per patient response [25]. A huge stimulus to the theranostics field has been the increase of nanotechnology in biomedical applications. Several breakthrough and innovations have continued to attract the attention of researchers worldwide [26]. Nanotechnology has tremendous potential to provide theranostic tools which enable diagnosis and therapy of various diseases. It offers versatility wherein properties of nanocarriers such as composition, size, shape and surface properties can be tuned to suit the intended application. C-dots are one of the most promising nanocarriers, as they may be tagged along with an imaging moiety and a therapeutic agent to enable simultaneous monitoring of drug release and therapeutic efficacy [27].

The aim of this review paper is to highlight the main applications of C-dots that are related to the theranostic area of research. This review does not aim to provide an exhaustive review of all research in the area of theranostics but provide examples of relevant applications. The review will also focus on C-dots future potential as theranostic agents including any areas that require further development (Fig. 1).

\section{General information of carbon dots}

\subsection{Synthesis of $\mathrm{C}$-dots}

C-dots are predominantly synthesized using two major approaches: Top-down and bottom-up (Fig. 2). Under the umbrella of these two approaches there are a variety of synthetic routes and methods prepared from various carbon precursors. These methods aim to fabricate C-dots with the advantages of being low cost, simple, and from the choice of numerous precursors, a summary of the advantages and disadvantages of different $C$-dot synthesis methods is presented in Table 1 . It is well accepted that the formation of C-dots from precursors occurs through four steps; dehydration, polymerization, carbonization, and passivation [28]. Most of the studies pursue facile, cost-effective, size-controllable and large-scale methods to synthesize C-dots that possess advanced functions with different compositions and structures [29]. After the synthesis stage, in addition to C-dots, usually unreacted precursors, side products, and large carbon particles are present. Thus, several cycles of centrifugation/ washing are required to remove remaining large carbon particles, as well as undesired products [3033]. The supernatant can be further purified by dialysis to obtain high-purity C-dots.

\subsubsection{Top-down methods}

Generally, in the synthesis of C-dots, the topdown approach refers to the breaking down or cleavage of larger carbon structures by chemical, electrochemical, or physical routes. These larger carbon precursors include graphite power [34], carbon rods [35], carbon fibers [36], carbon nanotubes [37, 38], carbon black [39], and even carbon soot [40]. The top-down cutting (cleaving) routes include electro-chemistry [41, 42], laser ablation [43], arc discharge [44], and hydrothermal/solvothermal/ special (chemical) oxidation [45, 46]. However, this approach has several drawbacks, which include the use of expensive materials, harsh reaction conditions, and long reaction times [47].

\subsubsection{Bottom-up methods}

The second major approach for fabricating C-dots refers to bottom-up methods which are the conversion of smaller carbon structures into C-dots [48]. There are a greater number of techniques for this approach that allow for more possibilities in using 


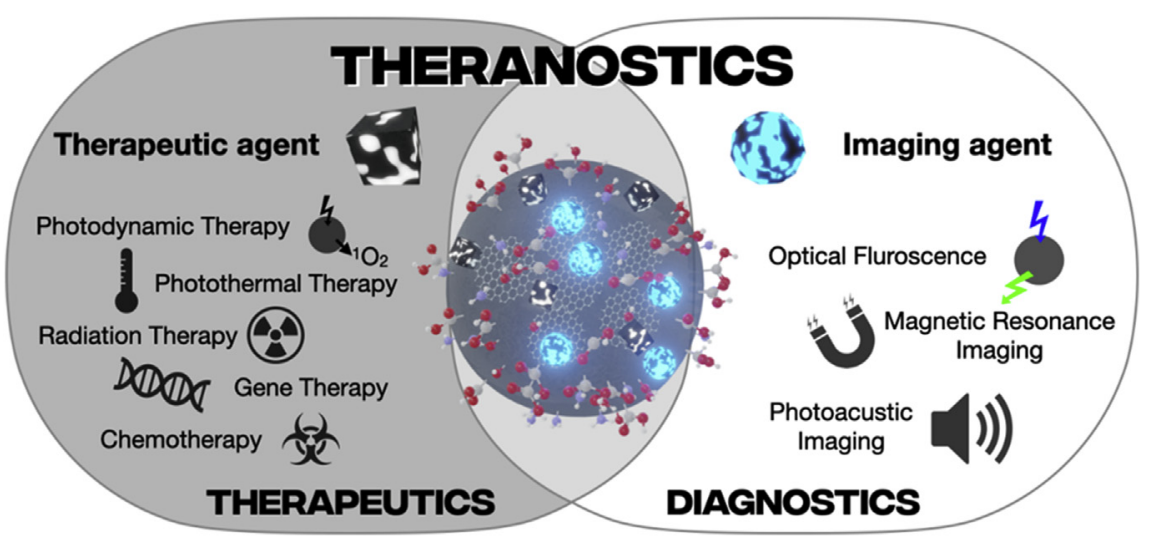

Fig. 1. Schematic representation of therapeutics, diagnostics, and theranostics of C-dots.

intricately designed precursors and preparation processes. Thus, C-dots can be tailored with particular attention to samples with well-defined molecular weight and size, shape and properties. As well as, greater control the bottom-up methods are usually low-cost and efficient for producing fluorescent C-dots on a large-scale, a prerequisite for practical applications of these novel C-dots [49]. There are many approaches for carrying out the dehydration and carbonization processes, such as hydrothermal [50], microwave [51], and combustion [52] methods, pyrolysis in concentrated acid [53], carbonization in a microreactor [54], enhanced hydrothermal microwave-hydrothermal [55] plasmahydrothermal [56] methods, and many others [57].

\subsubsection{Post synthesis modification}

C-dots can be modified either in the core structure by partial substitution of carbon with other elements or by surface functionalization referred to as passivation. Most C-dots have relatively low fluorescence efficiency compared to the conventional semiconductor quantum dots (QDs). The quantum yield of C-dots has been continually improved along the way, with the highest of $\sim 80 \%$ in aqueous solutions reached by blue fluorescent C-dots after nitrogen doping [58]. However, the quantum yield of other color fluorescent C-dots is mostly less than $20 \%$, much lower than traditional semiconductor QDs and organic dyes.

Various surface passivation methods are needed to improve the electronic and optical properties of C-dots. Doping of heteroatoms, including nitrogen, sulfur, boron, phosphorous and silicon, is considered as a most promising passivation method [59, 60, 61, 62]. Heteroatom doping not only improves photoluminescence (PL) properties of C-dots but also imparts further functionality to the doped Cdots. It is found that by doping heteroatoms into C- dots matrix, they can modulate the band structure of C-dots. Thus, they can expand their uses in applications such as fluorescent bioimaging [63]. As an example, Bourlinos et al. [64] demonstrated that Cdots doped with boron can significantly enhance the non-linear optical response when compared to undoped C-dots. While, Gong et al. [65] introduced gadolinium during the synthesis of $\mathrm{C}$-dots and the resultant products could be used as fluorescent labels and magnetic resonance imaging contrast agents. Apart from hetrodoping, the co-doping Cdots is another simple method to enhance their properties. Li et al. [66] prepared sulfur and nitrogen co-doped C-dots through a one-step microwave-mediated synthesis using citric acid and thiourea as the precursors, which presented significantly higher PL quantum yields compared to Cdots doped with nitrogen only.

C-dots possess various functional groups, which provide the possibility to be passivated by inorganic, polymeric and organic materials. Passivation or functionalization of C-dots surfaces is essential to enhance the fluorescence quantum yield [67]. During the passivation process, reactive sites, such as; hydroxyl, amine and carboxyl groups, are introduced on the C-dots surface for functional modification purposes [68]. Through these reactive groups, different specific inorganic, organic, polymeric, or biological materials can be linked to the C-dots surfaces via either covalent bonds, electrostatic interactions, or hydrogen bonds, which can then serve as platforms for specific sensing, drug delivery and other specific tasks [69-71].

Passivation agents containing nitrogen acting as auxochromes can dramatically improve the PL of Cdots [72, 73]. A good example of this, is the use of polyethyleneimine (PEI), which is a cationic polymer with a high density of amino groups that facilitates attachment of functional moieties onto the 


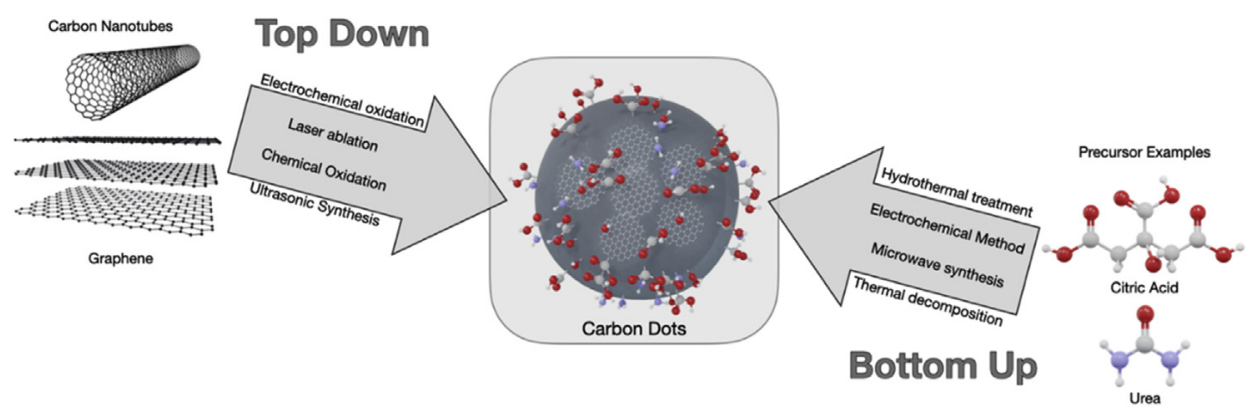

Fig. 2. Top-down and bottom-up approaches for the synthesis of C-dots.

C-dots. This also provides adsorption possibilities of anionic materials (such as folic acid) via non-covalent adsorption [74]. C-dots are modified with PEI through electrostatic interactions between the positively charged amino groups of PEI and the carboxyl (-COOH) groups on C-dots surface [75-77]. Liu et al. demonstrated PL enhancement of C-dots by passivating the surface with $\mathrm{PEI}$, the nitrogen-rich PEI served both as a passivation agent and a polyelectrolyte to condense DNA for gene therapy [78]. Other examples of polymer modification are now a more common occurrence. For example, Li et al. [79] investigated the effect of conjugating polyethylene glycol (PEG) chains, polyethylenimide-co-polyethylene glycol-co-polyethylenimide copolymer, and 4-armed PEG molecules. While, Su et al. reported surface passivated iodine doped C-dots with diamine-terminated oligomeric poly-(ethylene glycol) [80] and Wang et al. reported the application of (3-aminopropyl) trimethoxysilane as surface passivation agents to generate high PL quantum yield [81]. The comparison of quantum yield of Cdots before and after passivation verified that the passivation increases the luminescence efficiency of the C-dots [82].

\subsection{Structure of $\mathrm{C}$-dots}

Carbon materials, which include graphite, diamond, fullerenes, carbon nanotubes (CNTs), and graphene, have been well known for many years. To make these materials fluorescent, their size and surface chemical groups should be carefully modulated [83]. C-dots always possess at least one dimension less than $10 \mathrm{~nm}$ in size and fluorescence as their intrinsic properties. C-dots are commonly described in terms of a carbogenic core consisting of amorphous and crystalline parts with surface functional groups. As-prepared fluorescent carbon materials always consist of $\mathrm{sp}^{2} / \mathrm{sp}^{3}$ carbon, oxygen/ nitrogen-based groups, and post-modified chemical groups [84]. Nuclear magnetic resonance data indicates that the inner part of C-dots mainly consists of $\mathrm{sp}^{2}$ hybridized carbon atoms, while outer part is composed of $\mathrm{sp}^{3}$ hybridized carbon atoms [85].

Table 1. Summary of the advantages and disadvantages of different C-dot synthesis methods.

\begin{tabular}{|c|c|c|c|}
\hline & Methods & Advantages & Disadvantages \\
\hline \multirow[t]{4}{*}{ Top-down } & Electrochemical oxidation & $\begin{array}{l}\text { High purity, high yield, controllable size, good } \\
\text { reproducibility, low cost }\end{array}$ & $\begin{array}{l}\text { Complicated operation, especially when } \\
\text { doping with heteroatoms }\end{array}$ \\
\hline & Laser ablation & $\begin{array}{l}\text { Simple experimental setup, can produce particles } \\
\text { with different sizes and controllable morphology } \\
\text { by changing experimental parameters }\end{array}$ & Low yield and high cost \\
\hline & Chemcial oxidation & $\begin{array}{l}\text { Inexpensive equipment and can produce c-dots } \\
\text { are a large scale }\end{array}$ & $\begin{array}{l}\text { Numerous tedious steps, usually requires } \\
\text { toxic reagents and strong acid/base. } \\
\text { Non-uniform size distribution }\end{array}$ \\
\hline & Ultrasonic synthesis & Easy operation & High energy cost and instrumental wastage \\
\hline \multirow[t]{3}{*}{ Bottom-up } & Hydrothermal treatment & $\begin{array}{l}\text { Low cost, with simple control of key parameters } \\
\text { such as temperature, time and pressure of the } \\
\text { reaction vessel. The produced c-dots also have a } \\
\text { high quantum efficiency and are non-toxic. }\end{array}$ & Long synthesis duration and at a low yield \\
\hline & Microwave synthesis & $\begin{array}{l}\text { Short reaction time and it is easy to control the } \\
\text { size of the particles with the c-dots produced } \\
\text { being uniform in size distribution. }\end{array}$ & High energy cost \\
\hline & Thermal decomposition & $\begin{array}{l}\text { Easy operation, solvent-free, low cost and can } \\
\text { produce c-dots at a large scale }\end{array}$ & Low yield \\
\hline
\end{tabular}


Both $\mathrm{sp}^{2}$-and $\mathrm{sp}^{3}$-hybridized carbon atoms can be found within the C-dot, which was proven by the work of $\mathrm{Qu}$ et al. [86]. They prepared C-dots through a one-step microwave synthesis route contained both types of hybridized carbon atoms. The measurements from Raman spectra showed two broad bands at 1365 and $1575 \mathrm{~cm}^{-1}$ originating from the $D$ band ( $\mathrm{sp}^{3}$-hybridization) and $G$ band ( $\mathrm{sp}^{2}$-hybridization), respectively. Both types of carbon hybridization are also observed in the ${ }^{13} \mathrm{C}$ NMR data, where the signals between 30-45 ppm corresponded to $\mathrm{sp}^{3}$-hybridized carbon atoms, while the signals at $90-185 \mathrm{ppm}$ were associated with $\mathrm{sp}^{2}$ hybridized carbon atoms. The relative intensity of the spectrum bands can be used to evaluate the degree of graphitization and crystallization of the core [87].

The surface structure of C-dots depends not only on the synthesis method and preparation procedures, but also the on the selected precursors, such as; glycine, citric acid, urea and glucose [88-91]. Cdots are usually prepared in solution, and possess numerous functional groups such as epoxy, carbonyl, hydroxyl, and carboxyl on their surfaces, which give rise to their high hydrophilicity and readiness for functionalization with various organic, polymeric, or biological species.

\subsection{Special properties of C-dots}

C-dots exhibit unique properties that enable them to be used in various applications such as sensors, optronics and electrochemical luminescence. These properties can be tailored by controlling the size, shape, heteroatom doping or functionalization with biomolecules. When compared to organic dyes and traditional QDs, C-dots are advantageous in their photostability against photobleaching and blinking. Photobleaching is a major set-back for many fluorophores, in which the PL degrades over time with or without continuous excitation, limiting the shelflife of the fluorophores and long-term imaging capacity [92]. C-dots also tend to have lower toxicity, be chemically inert and have better biocompatibility when compared to inorganic semiconductor quantum dots. This allows for C-dots to be used as effective carriers for drug delivery or bioimaging, and thus is key to their potential in the theranostics area.

The optical properties of C-dots are perhaps their most important and most studied property. C-dots possess highly tunable photoluminescence (PL) from deep ultraviolet to near-infrared (NIR). Despite the diverse structures of C-dots, prepared from different approaches with different precursors,
C-dots usually share some similar optical properties in terms of absorption and fluorescence characteristics.

C-dots are an effective photon-harvester in the short-wavelength region due to light absorption by the conjugated electrons in a $\mathrm{sp}^{2}$ atomic framework. Typically, they show strong optical absorption in the UV region (230-320 $\mathrm{nm}$ ), with a tail extending into the visible region. The broad peak at $\sim 230 \mathrm{~nm}$ can be ascribed to the $\pi-\pi^{*}$ transition of aromatic $\mathrm{C}=\mathrm{C}$ bonds, whereas a shoulder at $300 \mathrm{~nm}$ is attributed to the $\mathrm{n}-\pi^{*}$ transition of $\mathrm{C}=\mathrm{O}$ bonds or other connected groups [93-95]. Moreover, the surface functional groups also play a role in determining the absorption wavelength of C-dots [96].

The origin of C-Dot photoluminescence has been related to $\mathrm{sp}^{2}$ domain size and the abundance of oxidized surface defects. While, it is stated that the PL mechanism also depends on the solvent environment and hydrogen bonding capability of the solvent, highlighting that emission can originate from surface defects to which energy migrates from the initially excited graphitic core [97, 98]. Also, graphitic domain size and surface oxidation can act together to red-shift C-dot emission [99]. However, this is often difficult to prove. Recent work by Nguyen et al. has aimed to unravel the PL mechanism of C-dots [100]. They investigated the emission wavelength and decay lifetime of solvothermally synthesized C-dots. They found that for solvothermal C-dots, it is surface-accessible spatially localized oxidized defects that are most likely carboxylates and phenolic hydroxyls, which are responsible for the fluorescence properties. While models for fluorescence redshift in solvothermally prepared C-dots based on degrees of $\mathrm{sp}^{2}$-hybridization of carbon surface domains exist, [101,102]. Nguyen et al. works data suggests that emission from oxygen-rich surface defects is the major mechanism, due to direct imaging of localized optically active defects and the sensitivity to $\mathrm{pH}$ of the C-dots. These observations support that it is the energy transfer from the graphitic core to highly localized surface defects that result in C-dot emission.

The surface functional groups can be determined using Fourier transform infrared spectroscopy or Xray photoelectron spectroscopy. Typically, moieties such as $\mathrm{C}-\mathrm{O}, \mathrm{C}=\mathrm{O}$ and $\mathrm{C}-\mathrm{OH}$ can exist on the surface and are usually introduced from the precursors during the synthesis process. The difference in size, composition or structure of the hybridization derivatives such as the functional groups and surface passivation can also alter the absorption characteristics of C-dots [103]. 
As mentioned, one of the most interesting optical properties of C-dots is their tunable PL across the entire visible spectrum. Different colored C-dots have been synthesized with different approaches, ranging from ultraviolet to red or even NIR emission but most commonly blue and green [104, 105]. For example, Jiang et al. prepared C-dots with blue, green, and red emission from distinctive phenylenediamine isomers using $365 \mathrm{~nm}$ excitation. The different precursors employed resulted in C-dots with different sizes and nitrogen contents, leading to differences in the PL emission [106]. Their tunable PL properties stem from the quantum confinement effect and edge or surface effects of their large rigid conjugated structure. The fluorescence spectra Cdots are usually broad due largely to the wide size distribution, and exhibition of large Stokes shifts due to the diverse electronic transition pathways. Often, C-dots exhibit excitation-dependent PL, where the PL bands red-shift with the increasing excitation wavelength. This is elegantly seen in the work of Pan et al. [107] who prepared C-dots from citric acid and formamide via a one-step microwaveassisted method. They increased the excitation wavelength from 330 to $600 \mathrm{~nm}$ and the corresponding emission covered the entire visible spectrum. However, C-dots have also been reported to show excitation-independent PL emission. The work of Zhang et al. [108] reported that C-dots hydrothermally synthesized with an emission wavelength of $418 \mathrm{~nm}$, which remained unchanged with the increasing excitation wavelength.

Interestingly, Li et al. [109] prepared C-dots from citric acid and urea by a hydrothermal method. These C-dots emissions could be tuned to be excitation-dependent or excitation-independent by changing the synthesis temperature. They found that C-dots prepared at $160{ }^{\circ} \mathrm{C}$ were excitation-independent due to suitable passivation of the surface traps on the C-dots, thus leading to a single transition mode. When the C-dots were synthesized at $240{ }^{\circ} \mathrm{C}$, the surface was passivated with a much smaller number of amino groups, resulting in surface traps with multiple energy levels, subsequently leading to excitation-dependent PL emission.

In addition to the conventional down-conversion fluorescence emissions, certain C-dots are also found to display two and multi-photon fluorescence emission [110-113], with up-conversion fluorescence reported [114] (anti-Stokes shift PL), which is orders of magnitude higher in efficiency than conventional fluorophores [115, 116].

Up-conversion fluorescence emission is an optical phenomenon wherein the fluorescence emission wavelength is shorter than the excitation wavelength. This is particularly attractive for in vivo imaging due to the deep-tissue penetration ability of long excitation wavelengths especially in the NIR region, and for molecular imaging with high spatialresolution, low background interference, and low photon-induced toxicity because of the highly localized nonlinear photon adsorption process. However, it should be pointed out that some of the apparent up-conversion fluorescence emissions of C-dots reported might be artefacts. Gan et al. [117] revisited several publications that reported the upconversion PL in C-dots under excitation from a xenon lamp. Experiments have revealed that the PL was an artificial up-conversion emission, which was essentially excited by the second-order diffraction light of wavelength $(\lambda / 2)$ coexisting with the excitation light of wavelength $(\lambda)$ in the light source. Therefore, it is of great importance to establish a proper characterization system before one can truthfully investigate the up-conversion PL properties of C-dots.

\section{Analytical applications of C-dots (diagnostic)}

C-dots have been used for a variety of biomedical applications due to their unique optical properties, their large surface area and the flexible ability for surface functionalization. Although, there are still currently some biosafety concerns about the use of C-dots, up until now no acute toxicity or morphological changes have been found from in vitro cytotoxicity studies of numerous series of cell lines [118]. More recently, in vivo studies have also indicated the low toxicity and good biocompatibility of C-dots [119].

\subsection{Imaging}

C-dots tend to be superior to the current organic dyes and semiconductor QDs due to their distinctive advantages marked by multicolor emission profile, small sizes, low cytotoxicity, good biocompatibility, and excellent photostability, as C-dots do not tend to photobleach unlike most of currently used fluorescence tracking dyes [120]. These qualities make C-dots desirable alternatives to probe biological systems both in vitro and in vivo [121]. Cdots prepared via a dry heating approach have also been used for elective labeling of $E$. coli and folate receptor positive cancer cells (Fig. 3) [122]. The fluorescent-core C-dots were synthesized through carbonization of ammonium citrate via dry heating. Then, the C-dots were heated with mannose and folic acid to prepare mannose-functionalized C-dots 


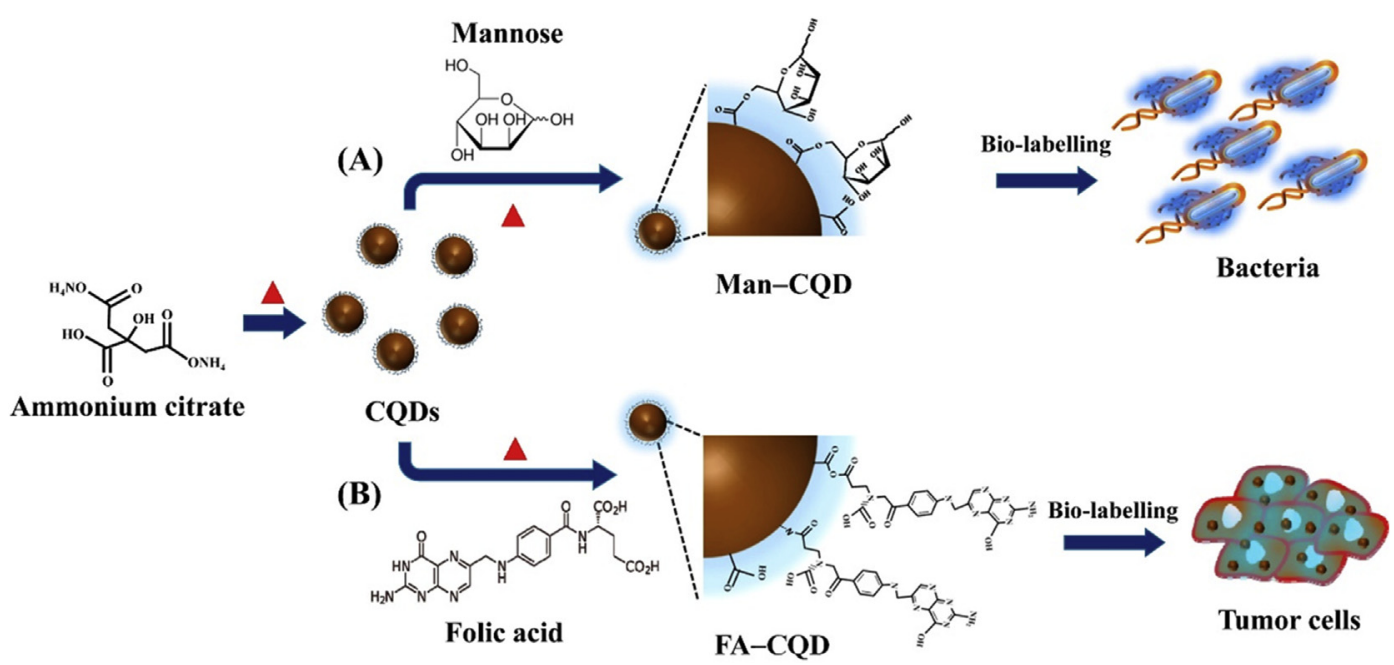

Fig. 3. Synthesis of (A) mannose-functionalized carbon quantum dots (Man-CQDs) and (B) folic acid-functionalized carbon quantum dots (FA-CQDs) for the selective labeling of (A) E. coli and (B) tumor cells. Reproduced from Ref. [122] with permission from Elsevier.

and folic acid-functionalized C-dots through a dehydration reaction in the solid state.

Other researchers have developed and tested Cdots for the imaging of the cervical cancer cell line (HeLa). Pan et al. [123] and Hu et al [124] developed $\mathrm{C}$-dots from the thermal reduction of mono-layer graphene oxide sheets with $\mathrm{H}_{2} \mathrm{SO}_{4}$ and $\mathrm{HNO}_{3}$ and hydrothermal treatment graphene oxide in the presence of ammonia, respectively. These C-dots did not show any significant toxicity to the cells and were mostly situated in the cytoplasmic region. Ge et al. [125] prepared red-emissive C-dots with broad absorption in the region from 400 to $750 \mathrm{~nm}$ from polythiophene phenylpropionic acid. They intravenously injected the C-dots in HeLa-tumor bearing mice and observed that the C-dots were mostly accumulated inside the tumor.

As seen with the previous examples of cell imaging, most of the C-dots are localized only in the cytoplasm and cell membrane. In general, the incorporation of materials into cells is predominately dependent on the size and the charge of the material [126]. C-dots can be internalized into the cytoplasm quite easily thanks to their small size $(<10 \mathrm{~nm})$ [127]. However, C-dots are mainly negatively charged because of predominance of surface carboxylate groups, and thus cannot easily enter the cell nucleus. However, the cell nucleus is critical to various important cellular events, including metabolism, heredity and reproduction [128]. Therefore, nucleus staining is the first step in revealing more information about the nucleus morphology and the nuclear function. Thus, having the fluorescence agent in the cell nucleus is a very desired function [129]. This was achieved for the first time by Datta et al. who reported the uptake of C-dots into the cell nucleus [130]. The prepared C-dots entered the nucleus due to their strong positive charge stemming from the quaternary ammonium (betaine) precursor combined with their small size. This charge effect was also witnessed in the work of Kang et al. [131] who used dopamine, neutralization by heat to produce biomolecule-mimicking nitrogendoped C-dots. Cell imaging with four kinds of cancer cells proved the nucleus-staining efficiency of these C-dots. The cell lines included A549, HepG2, rat pheochromocytoma cells (PC12), and breast cancer cells (MD-MBA-231).

Some interesting work from Hua et al [132] found that the addition of varied metal ions during the hydrothermal treatment of p-phenylenediamine (pPDA) led to the formation of fluorescent C-dots with emission wavelengths up to $700 \mathrm{~nm}$, however, these C-dots remained metal free, with the metal acting as a 'catalyst'. In vitro and in vivo experiments demonstrated that when Nickel was used with pPCDs, the resulting C-dots are highly biocompatible and can realize real-time, wash-free, and high-resolution imaging of cell nuclei and highcontrast imaging of tumor-bearing mice and zebrafish. More work from this research group can be seen within this area, with a number of publications in the area of cancer cell imaging [133-136].

C-dots have also been used in two-photon fluorescence imaging. This technique allows for visualization of living tissue at depths unachievable with conventional (one-photon) fluorescence or confocal microscopy, as well as, a lower tissue autofluorescence background and less photodamage by avoiding harmful UV or blue excitations. The work 
of Sun et al [137] first demonstrated the potential of C-dots for cell imaging with two-photon luminescence microscopy. They showed the two-photon absorption cross-section of C-dots passivated by an imine polymer and then compared them to the bestperforming core-shell quantum dots. This was further witnessed by Tian's group who proposed Cdots for use in living cells and tissues [138]. These responsive $\mathrm{pH}$ variations used a receptor molecule covalently bound to the $\mathrm{C}$-dot surface. As the acidity of the C-dot system decreased, the fluorescence signal became more intense. The excitation was at $800 \mathrm{~nm}$, while the emission was at $498 \mathrm{~nm}$; excitation at $800 \mathrm{~nm}$ are preferable for tissue penetration and this system was able to be used in living tissues at depths of between $65-185 \mu \mathrm{m}$.

\subsection{Sensing}

C-dots have been employed by researchers as a bio- and chemical-sensing materials due to their unique properties like excitation-dependent emission, higher photostability, low cytotoxicity and aqueous solubility [139]. This sensing usually occurs by a change in their fluorescence properties that can take place via different mechanisms, such as resonance energy transfer, inner filter effect, and photoinduced electron and charge transfer. C-dots can be used for sensing of several biological molecules and intracellular metal ions, such as hydrogen peroxide $\left(\mathrm{H}_{2} \mathrm{O}_{2}\right), \mathrm{Fe}^{3+}$, glucose, vitamin B12, L-cysteine, and galactose, etc. Several researchers have developed hydrogen peroxide $\left(\mathrm{H}_{2} \mathrm{O}_{2}\right)$ sensing, $\mathrm{Wu}$ et al. [140] used C-dots derived from L-glutamic acid for the detection of $\mathrm{H}_{2} \mathrm{O}_{2}$. These $\mathrm{C}$-dots possessed peroxidase-like activity, which could be used for $\mathrm{H}_{2} \mathrm{O}_{2}$ detection $(\mathrm{LOD}=20 \mu \mathrm{M})$ in the presence of 2, 2'azino-bis(3-ethylbenzothiazoline-6-sulphonic acid). While, Qian et al. used hydroquinone, and $\mathrm{SiCl}_{4}$ derived $\mathrm{C}$-dots as the sensor for $\mathrm{H}_{2} \mathrm{O}_{2}, \mathrm{Fe}^{3+}$ and melamine. The detection of $\mathrm{H}_{2} \mathrm{O}_{2}$ was attained by an electron transfer mechanism between $\mathrm{Si}$-doped $\mathrm{C}$ dots and $\mathrm{H}_{2} \mathrm{O}_{2}$, while both electron and energy transfer mechanisms were utilized for detecting $\mathrm{Fe}^{3+}$. Formation of a stable adduct between $\mathrm{H}_{2} \mathrm{O}_{2}$ and melamine following melamine addition recovered the fluorescence and thereby acted as a sensitive detector for melamine as well [141]. Finally, Shan et al. used Boron-doped C-dots for selective detection of $\mathrm{H}_{2} \mathrm{O}_{2}$, and the detection limit was $8.0 \mu \mathrm{M}$. These C-dots could also be used for detection of glucose in the presence of glucose oxidase which produces $\mathrm{H}_{2} \mathrm{O}_{2}$ via oxidation of glucose [142].

Other biological molecules could be detected in human urine such as folic acid and galactose. For folic acid detection, Chen et al. [143] fabricated Cdots from lactose and $\mathrm{NaOH}$ by simple heating. They observed that their fluorescence of prepared C-dots fluorescence was quenched upon binding with folic acid. For galactose, Yang et al. [144] reported the use of boronic acid functionalized C-dots. The boronic acid moiety present on the C-dot surface reacted with cis-diol units of galactose to give cyclic boronate esters, which has the ability to quench the fabricated C-dots.

The detection of biological iron $\left(\mathrm{Fe}^{3+}\right)$ is also possible, for example Lan et al. [145] used hydroxyl and carboxyl groups to passivate fullerene (C60) derived C-dots. These groups interact with $\mathrm{Fe}^{3+}$, thereby quenching the fluorescence.

\subsection{Metal ion detection}

Apart from biological metal ions, C-dots can be used for direct chemical sensing of metal ions. These interactions with the C-dots surface functional groups lead to the formation of new electron-hole rearrangement, which result in the change of the fluorescence nature of the C-dots. This C-dot property can be utilized for sensing different types of metal ions, this review paper will mainly focus on C-dots used for mercury sensing as example, however, there is a sizable body of research in this area, with different meta ions, such as $\mathrm{Hg}^{2+}$ [146-152], $\mathrm{Ag}^{+}$[153-157], $\mathrm{Cu}^{2+}$ [158], and $\mathrm{Fe}^{3+}$ [159-163].

C-dots have been employed for the detection of the highly toxic heavy metal ion mercury $\left(\mathrm{Hg}^{2+}\right)$ on several occasions. Zhou et al. demonstrated the use of unmodified C-dots for the detection of $\mathrm{Hg}^{2+}$ and biothiols (glutathione, cysteine, and homocysteine) with higher selectivity and sensitivity. They observed that the addition of $\mathrm{Hg}^{2+}$ to C-dots caused fluorescence quenching. However, subsequent addition of biothiols to the $\mathrm{Hg}^{2+} / \mathrm{C}$-dots recovered the fluorescence via the removal of $\mathrm{Hg}^{2+}$ ions, which has a high affinity towards the thiol ( $-\mathrm{SH})$ groups [164]. After that Guo et al. synthesized C-dots from sodium citrate/citric acid via hydrothermal treatment for the selective and sensitive detection of $\mathrm{Hg}^{2+}$ ions [165]. $\mathrm{C}$-dots prepared from histidine hydrochloride in the absence or presence of halides $(\mathrm{Cl}, \mathrm{Br}$, and I) through an electrochemical approach was used for quantitation of $\mathrm{Cu}^{2+}$ [166]. The time-evolution UV-vis absorption and photoluminescence (PL) spectra were recorded to investigate the formation of $\mathrm{C}$-dots (Fig. 4). Halides (Cl, Br, and I) induced surface defects and reaction rate were suggested. The $\mathrm{C}$-dots were selective and sensitive (down to $0.22 \mu \mathrm{M}$ ) for the detection of $\mathrm{Cu}^{2+}$ based on analyte induced 


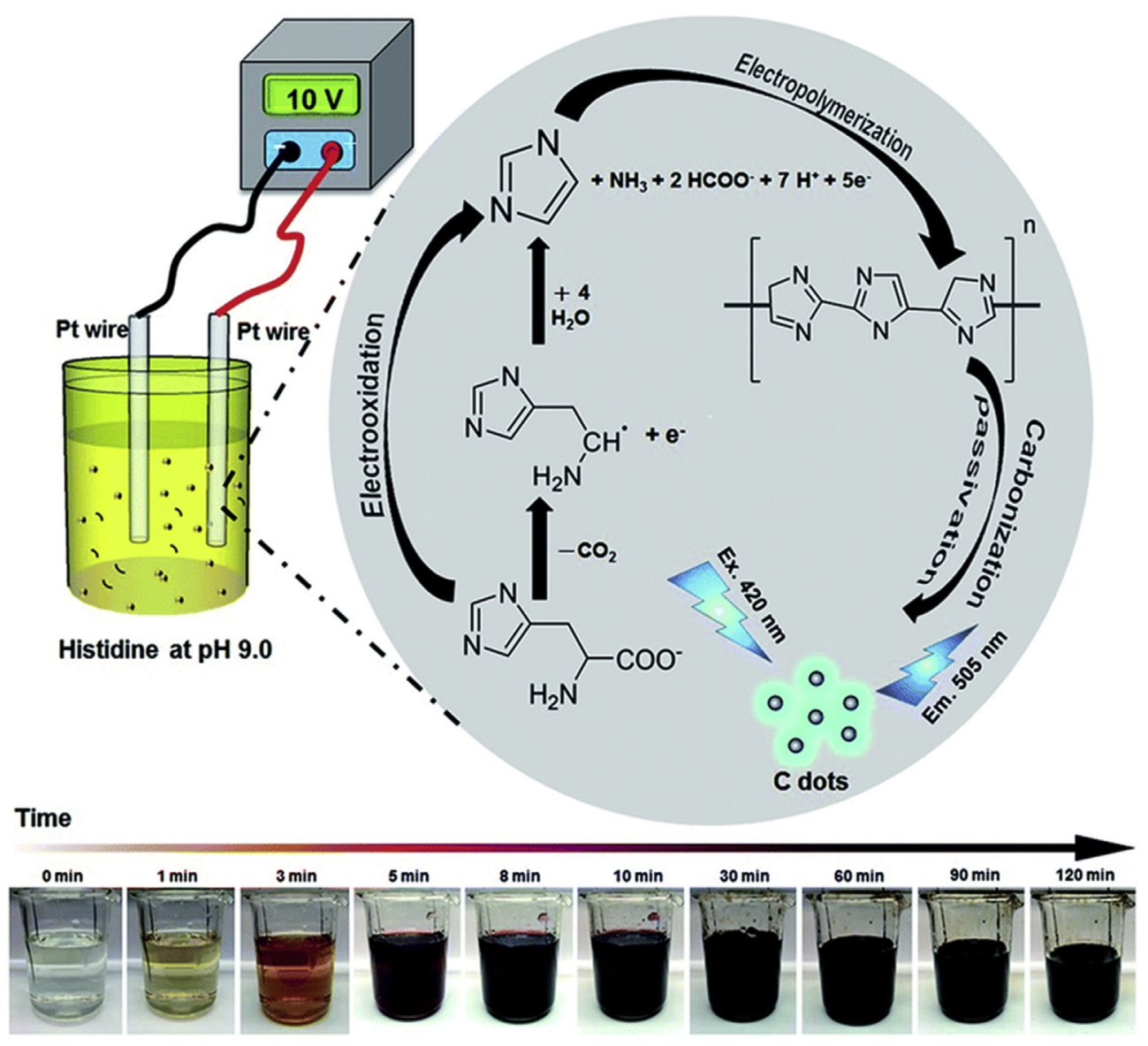

Fig. 4. Schematic representation of preparation of C dots from histidine hydrochloride through an electrochemical route. Reproduced from Ref. [166] with permission from Royal Society of Chemistry.

fluorescence quenching. Practicality was validated by the analyses of tap, lake, and sea water samples, with negligible matrix effects.

\subsection{Other recent diagnostics}

Recently, C dots have been shown to be useful for the quantitation of abused drugs. C-dots prepared from L-arginine through a hydrothermal route have been used for quantitation of 4-chloroethcathinone [167]. The study found that $\pi$-conjugated keto or ester compounds can induce fluorescence quenching of C-dots through an electron transfer process. At $\mathrm{pH} 11$, the C-dot probe is selective for cathinones and a fluorescence assay using C-dots in conjunction with liquid-liquid extraction has been developed for screening illegal date rape drugs, such as nimetazepam, flunitrazepam, clonazepam, and nitrazepam (Fig. 5) [168]. To detect these hydrophobic date rape drugs, hydrophobic C-dots were synthesized from D-phenylalanine Detection of the analyte was realized by observing the fluorescence quenching of hydrophobic C-dots at $430 \mathrm{~nm}$ when excited at $365 \mathrm{~nm}$.

For diagnostic applications in infectious tissue, platinum ion $\left(\mathrm{Pt}^{4+}\right)$-capped fluorescent C-dots coupled with loop-mediated isothermal amplification (LAMP) were developed to detect dual MRSA (methicillin-resistant Staphylococcus aureus) genes (Fig. 6) [169]. The C-dots containing nitrogen and chloride residues were prepared from spermidine trihydrochloride via a simple one-step dry heating method. Co-doping of nitrogen and chloride cooperatively mediated the coordination of $\mathrm{C}$-dots with $\mathrm{Pt}^{4+}$. C-dots $/ \mathrm{Pt}^{4+}$ probe facilitated the doublestranded DNA (dsDNA)-induced fluorescence quenching of $\mathrm{C}$-dots with the detection of as few as 10 copies of the MRSA gene (mecA and femA).

\section{Biomedical applications of C-dots (therapeutic)}

Drug delivery requires designing systems that are capable of transporting the drug to a specific target 


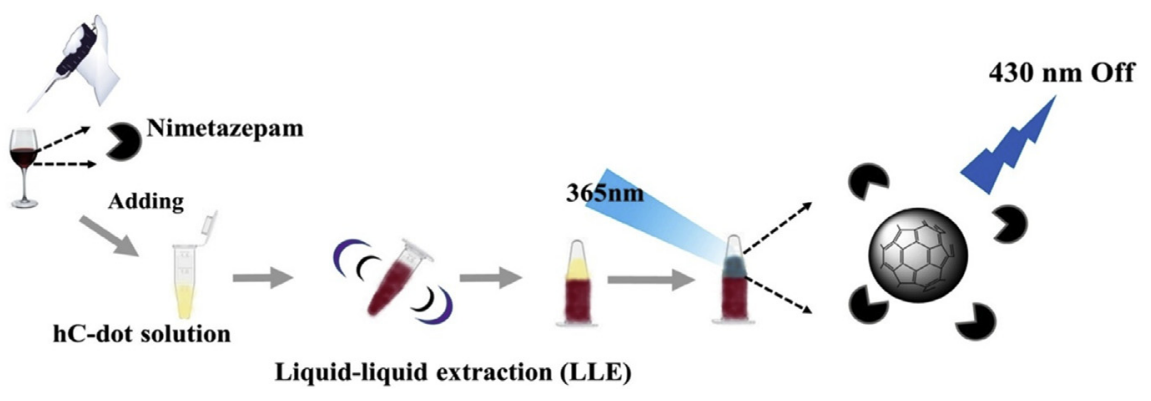

Fig. 5. Schematic representation of a rapid and simple hC-dot sensing system in conjunction with LLE for quantitation of nimetazepam. Reproduced from Ref. [168] with permission from Elsevier.

in the body and facilitating suitable interactions of the drug with the target. Nano-structured materials conjugated with the drug(s) can improve the drug delivery systems with respect to the drugs absorption, distribution and elimination [170]. Application of nanotechnology in drug delivery systems may result in many drug targeting advantages such as delivery to a specific cell or tissue, enhanced delivery of drugs with low water solubility, delivery of two or more drugs or therapeutic modality for different therapy simultaneously, transferring of large macromolecule drugs, and monitoring of the drug site using imaging agents on the drug carrier [171]. C-dots can not only act as smart drug delivery systems, but depending upon their starting material, they can also be used medicines. In this concern, Chang et al. [172] prepared C-dots from ginger which exhibited high efficiency to kill HepG2 cells with lower toxicity towards normal mammary epithelial cells (MCF-10A) and normal liver cells (FL83B).

\subsection{Cancer}

The inherent properties (fluorescence emission, small size and resultant cell permeation, nontoxic, chemical inertness, aqueous solubility) of C-dots are often superior to conventional drug delivery systems. They also have relatively simple functionalization, thus, excellent drug loading potential. Several researchers have employed C-dots in drug delivery systems [173-176]. For instance, many researchers have delivered anticancer drugs with doxorubicin (DOX) a popular choice. Tang et al. [112] developed a C-dots system which can efficiently deliver the loaded DOX at the desired point of interest. The high fluorescence resonance energy transfer (FRET) efficiency phenomenon between Cdots and DOX results in a decrease in fluorescence intensity of the C-dots and an increase in DOX fluorescence. This FRET based two-photon imaging C-dots-DOX system provides a real time monitoring of the drug release profile. When the DOX is

(A)

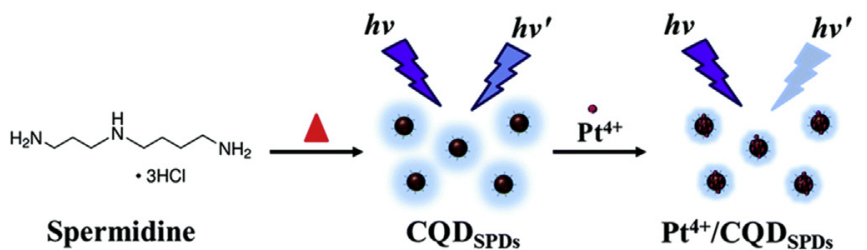

(B)

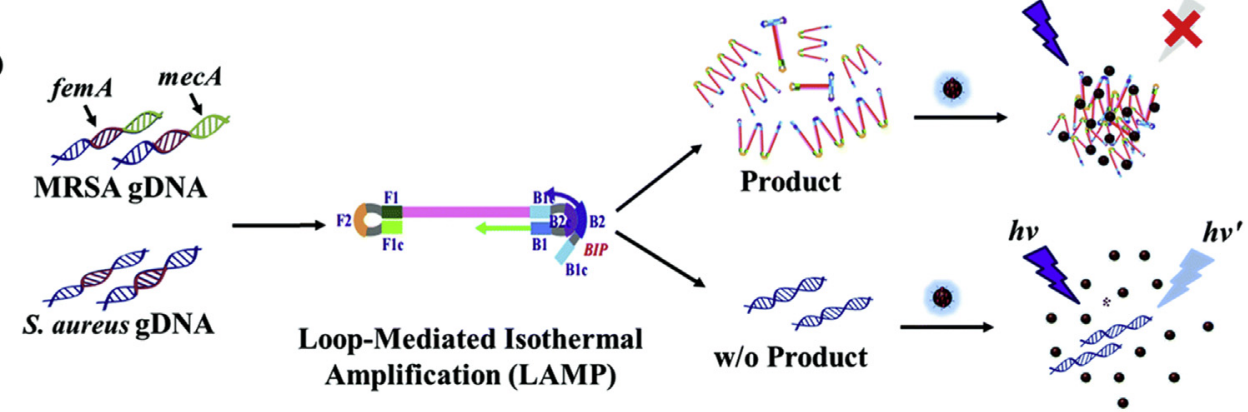

Fig. 6. Schematic of (A) synthesis of $C Q D_{S P D s}$ from spermidine, and complexation of Pt $t^{4+}$ and (B) detection of the LAMP products of MRSA-infectious samples by $\mathrm{Pt}^{4+}$-capped $C Q D_{S P D s}$ through DNA-induced fluorescence quenching. Reproduced from Ref. [169] with permission from Royal Society of Chemistry. 
detached from the C-dots, the FRET phenomenon weakens between the DOX and C-dot and subsequently the fluorescence intensity increases. Yang et al. [177] produced C-dots passivated with polyamine-containing organosilane molecules that contained DOX. These C-dots had an extremely high drug loading capacity $(62.8 \%)$, while the surface hydroxyl groups still ensured good water-dispersibility. These materials were internalized by human breast cancer cells (MCF-7), where, the DOX could gradually detach from the surface of C-dots and enter into the cell nucleus, while the C-dots themselves still resided in the cytoplasm.

C-dots can also be used for magnetic resonance imaging (MRI) while having the benefit of drug delivery and fluorescence imaging. The MRI combined with fluorescence imaging would have the benefit of superior tissue penetration and spatial resolution of MRI and easy microscopic tissue examination of the fluorescent imaging. For example, $\mathrm{C}$-dots have been synthesized incorporated with $\mathrm{Eu}^{3+}, \mathrm{Mn}^{2+}$, and $\mathrm{Gd}^{3+}$ ions into the dots. Zou and co-workers developed $\mathrm{Gd}^{3+}$ doped C-dots for MRI guided radiotherapy of tumors. The Gd-doped Cdots demonstrated a relatively large circulation time of $6 \mathrm{~h}$, efficient in-vivo biodistribution and passive tumor targeting. The primary results on in vivo tumor xenograft model showed that dose enhancement of Gd-doped C-dots leads directly to efficient tumor control by the radiosensitized radiotherapy [178].

\subsection{Gene therapy}

Although the delivery of small molecule drugs has been extensively studied using C-dots, there are now reports of $\mathrm{C}$-dots being used as gene carriers. Gene therapy has seen several advancements as a therapeutic approach to cure many debilitating diseases. Until now, viral vectors are the most efficient vector in delivery of genes and $\sim 70 \%$ of clinical gene therapy trials use viral vectors [179]. However, there are major problems related to viral vectors such as severe immunogenicity response, random genomic integration, very limited capacity to accommodate long nucleic acids and high production costs [180]. Yu et al. [181] designed a C-dot based multifunctional delivery system that can deliver both drugs and genes. In the design of their vector, they synthesized amphiphilic C-dots by attaching alkyl epoxide to the amino groups on the surface of PEI derived C-dots. They then used green fluorescence protein (GFP) expression and flow cytometry data to confirm that the prepared Cdots had higher transfection efficacy than a conventional vector (Lipofectamine-2000) in cancerous A549 cells.

\subsection{Photodynamic therapy (PDT) and photothermal therapy (PTT)}

Apart from the utilization in the delivery of drugs and genetic materials, other modes of treatment have been employed to design theranostic C-dots for photodynamic therapy (PDT) and photothermal therapy (PTT) [182]. PTT and PDT are a new class of therapeutic strategy which involves laser light for treatment of disease. In case of PTT, the photoabsorber should have a strong absorbance in the NIR region to convert the absorbed energy into heat. The generated local heat from photons leads to the thermal ablation of the target cells and subsequent cell death. Compared with other traditional therapeutic approaches for cancer treatment, like aggressive surgery, chemotherapy or radiotherapy, PTT offers distinctive advantages; such as being non-invasive, highly specific and having precise temporal selectivity [183]. In the last few years many research groups have been exploring the therapeutic efficacy of PTT for treatment of cancer. PTT can destroy cancer cells directly at the primary tumor site or local metastasis in nearby lymph nodes to fight the initial stage of cancer metastasis. The therapeutic effectiveness of PTT significantly depends on the conversion of light into heat in presence of photothermal agents, especially nanodimensional agents. It is also believed that due to the inherent C-dot structure, such as large number of $\pi$ electrons, which result in strong electron-electron interactions and weak electronphonon interactions. This suggests that most of the absorbed light can be transformed into heat by various non-radiative pathways.

Along with PTT, C-dot based PDT has gained noteworthy attention. PDT involves three main components, which include a photosensitizer, a light source and a reactive oxygen spices (ROS). In most of the cases the light source is a laser which excites the photosensitizer and produces radicals or ROS. These species include ${ }^{1} \mathrm{O}_{2}, \mathrm{O}_{2} \bullet$, and $\bullet \mathrm{OH}$, which are highly cytotoxic to cells [184] and ultimately destroy the diseased tissue site. In this context, C-dots have been used extensively to deliver photosensitizer agents to the diseased tissue site due to their ease of synthesis, surface functionalization, good carrying capacity and excellent biocompatibility. An example of this is the work of He et al. [185] who prepared C-dots from chitosan and diketopyrrolopyrrole, that can generate singlet oxygen species $\left({ }^{1} \mathrm{O}_{2}\right)$ by single laser irradiation. 
Their fabricated C-dots showed good hydrophilicity and biocompatibility, both in vitro and in vivo. Their findings presented that the prepared C-dots were non-toxic to HepG2 cells at concentrations up to $200 \mu \mathrm{g} \mathrm{mL}^{-1}$, without laser irradiation, whereas with laser irradiation at $540 \mathrm{~nm}, 100 \mu \mathrm{g} \mathrm{ml}^{-1}$ was enough to kill $50 \%$ of the cells. Another example, is shown in the work from Hua et al. who fabricated C-dots by a one-step hydrothermal treatment of chitosan, ethylenediamine and mercaptosuccinic acid. These Cdots were conjugated with a photosensitizer rose bengal (RB) with the resultant $\mathrm{C}$-dots achieving efficient cellular uptake and mitochondrial targeting/accumulation, allowing for mitochondria-targeted photodynamic therapy [186].

\subsection{Microorganisms}

Therapeutic application of C-dots in infectious disease has been demonstrated in the treatment of bacterial keratitis (BK) [187]. Super-cationic C-dots $\left(\mathrm{CQD}_{\mathrm{Spds}}\right)$ were synthesized via direct pyrolysis of spermidine trihydrochloride powder. The CQD $\mathrm{Spds}_{\mathrm{S}}$ were shown to effectively kill both gram-positive and gram-negative bacteria, as well as multidrug resistant bacteria, such as methicillin-resistant $S$. aureus (MRSA). Mechanism of antibacterial activity of $\mathrm{CQD}_{\mathrm{Spds}}$ was attributed to highly positive charge ( $\zeta$-potential ca. $+45 \mathrm{mV}$ ), which caused severe disruption of the bacterial membrane and bacterial death. In vivo antibacterial study in the treatment of BK in rabbit eyes demonstrated ocular administration of $\mathrm{CQD}_{\mathrm{Spds}}$ can induce the opening of the tight junction of corneal epithelial cells and treat $S$. aureus-induced eye infection (Fig. 7).

In addition, the use of $\mathrm{C}$-dots in combating viral infection has been demonstrated by Huang's group
[188]. Using a simple dry heating method, curcumin was converted to curcumin C-dots (Cur-CQDs), which possessed polymer-like curcumin and slightly degraded (pyrolytic) curcumin polymers or molecules on the surfaces. Cur-CQDs were effective against EV71 infection in RD cells (human rhabdomyosarcoma). Cur-CQDs can block the attachment of the EV71 virus to the cell membrane of RD cells (Fig. 8), and also inhibit the translation of EV71- and EV71-induced eIF4G cleavage and decrease the expression of phosphorylated p38 kinase. In vivo animal studies demonstrated that Cur-CQDs are an effective antiviral agent for protecting newborn mice against EV71 infection. Another interesting area is the use of C-dots to differentiate and distinguish bacteria types [189]. This enables fast gram-type identification and even selective inactivation of bacteria. Yang et al. [190] elegantly showed their Cdots were adsorbed onto gram-positive bacteria, which ultimately led to its inactivation. More information on this area is covered in the review paper from Lin et al. [191] who presents a detailed summary of the recent advancements of C-dots for sensing and killing microorganisms, including bacteria, fungi, and viruses.

\section{Problematic areas in theranostics}

Although theranostic C-dot systems are promising for management of a multitude of disorders, for their successful clinical translation there are still multiple issues that need to be resolved. These Cdot systems tend to not be as simple as conventional drug delivery systems. This is partly due to their multifunctional character and the associated complexities of their ultra-small size. The issue of how these can be accurately characterized and their tissue interactions are of key importance. In order

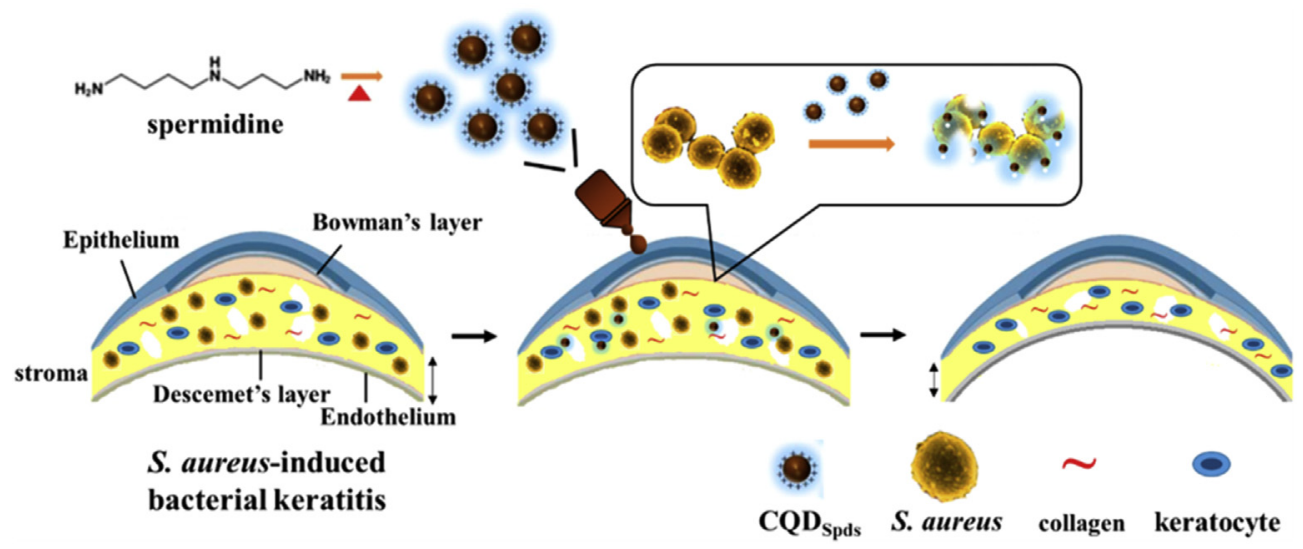

Fig. 7. Schematic representation of one-step dry heating synthesis of fluorescent carbon quantum dots $\left(C Q D_{S p d s}\right)$ from spermidine and their treatment for S. aureus-induced bacterial keratitis. Reproduced from Ref. [187] with permission from American Chemical Society. 
(A)

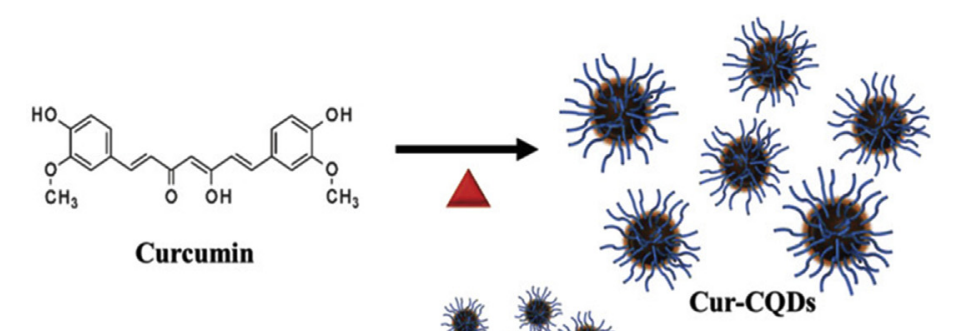

(B)

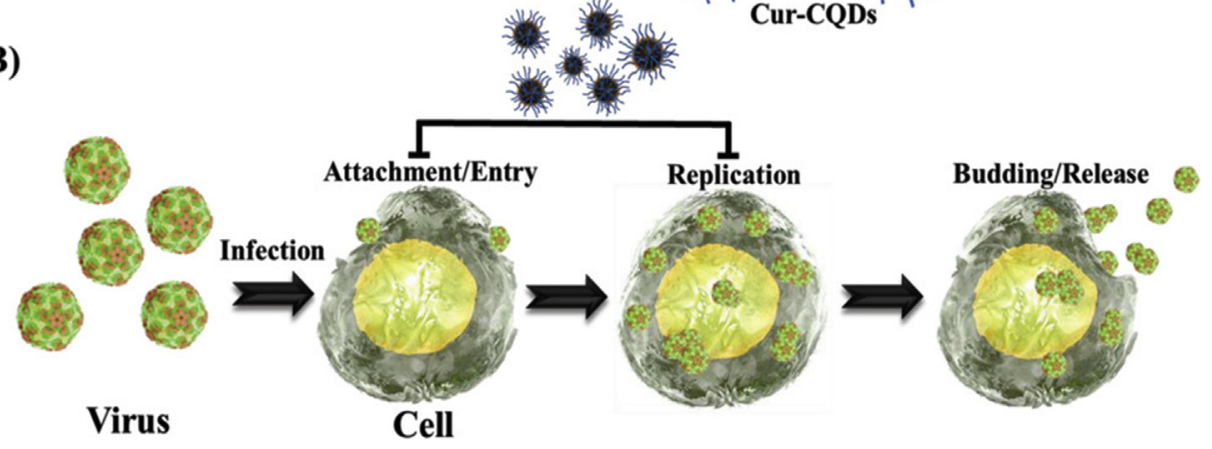

Fig. 8. Schematic representation of (A) the one-step synthesis of Cur-CQDs and (B) their antiviral applications. Reproduced from Ref. [188] with permission from Wiley- $\mathrm{VCH}$.

to shed light on the mechanisms of elimination, the complete journey of the theranostic agents must be tracked from administration to elimination. Plus, the interactions at cellular and sub-cellular levels should be identified. The main aim of C-dot systems is to achieve enhanced efficacy and minimal toxicity through simple elimination by the body's natural elimination mechanisms, such as excretion through the kidneys. The targeting site of these theranostic agents is vital and usually achieved by tethering molecules on the C-dot surface. The optimization and scale of these processes to produce consistent and reproducible materials is a challenge with certain systems. For example, the fabrication method should preserve both the diagnostic or imaging agent as well as the drug or therapeutic component. This issue is extremely pertinent with certain therapeutics such as genetic material and peptides. Most of these C-dot theranostic systems are intended for parenteral administration, and therefore, require sterilization. Thus, sterilization method should not have any undesirable effects on the components. Gaining regulatory approval for such products is often difficult and expensive owing to the complicated composition and employment of the components. Lastly, utilization of the multiple ingredients, intricate fabrication, and convoluted characterization may rapidly increase the cost of the system to such an extent that the affordability of these systems is reduced.

\section{Conclusion and future theranostic potential}

Although discovered by accident, C-dots continue to gather significant attention in multiple fields due to their inherent properties. They have exceptional photoluminescence and good water dispersibility. They are widely used in cellular imaging, catalysis, electronics, biosensing, power, detection of small molecules, targeted drug delivery, and other biomedical applications. The field of nanotheranostics is growing at a rapid pace driven by the advances in material science, molecular biology, nanotechnology and formulation development. Cdot based theranostic agents have the ability to dramatically transform the management of numerous conditions such as infections, inflammation, neurodegenerative disorders, cardiovascular diseases, targeted treatment, and monitoring of therapeutic effect. One of these areas where C-dot theranostic systems have been extensively explored is in the field of oncology. However, C-dot theranostic systems still have a long way to go, the simple combination of components such as imaging agents, therapeutics and targeting ligands within C-dots is not sufficient. One potential new carbon-based material that can provide multiple functions is liposome-like C-dots [192,193]. The liposome-like C-dots consisting of thousands of individual C-dots possess stronger fluorescence intensity when compared to individual C-dots. Like traditional Cdots, they can be used to load drugs such as doxorubicin (anticancer drug) and efficiently penetrate 
cancer tissues (unreported results). The biocompatible and stable liposome-like $C$ dots can also be used to load various hydrophobic or hydrophilic cancer drugs. There are still a number of problematic areas that require extensive evaluation of $C$ dots. To solve these problems, detailed studies must be carried out, which address in vivo safety, pharmacokinetics, distribution, compatibility of the components with each other. Effect of C-dot fabrication methodology on the stability of each component and development of scalable C-dot production are vitally important. All of these concerns need to be addressed before we see further day to day clinical use of C-dots for theranostic applications.

\section{Conflicts of interest}

The authors declare no conflicts of interest.

\section{Acknowledgements}

We are grateful to the Ministry of Science and Technology (MOST) of Taiwan for providing financial support for this study under contracts 107-2113M-002-015-MY3, 108-2622-M-002-002-CC2, and 108-2638-M-002-001-MY2.

\section{References}

[1] Xu X, Ray R, Gu Y, Ploehn HJ, Gearheart L, Raker K, et al. Electrophoretic analysis and purification of fluorescent single-walled carbon nanotube fragments. J Am Chem Soc 2004;126:12736-7.

[2] Li YB, Bai GX, Zeng SJ, Hao JH. Theranostic carbon dots with innovative NIR-II emission for in vivo renal-excreted optical imaging and photothermal therapy. ACS Appl Mater Interfaces 2019;11:4737-44.

[3] Hsu PC, Shih ZY, Lee CH, Chang HT. Synthesis and analytical applications of photoluminescent carbon nanodots. Green Chem 2012;14:917-20.

[4] Roy P, Chen PC, Periasamy AP, Chen YN, Chang HT. Photoluminescent carbon nanodots: synthesis, physicochemical properties and analytical applications. Mater Today 2015;18:447-58.

[5] Wu WC, Chen HYT, Lin SC, Chen HY, Chen FR, Chang HT, et al. Nitrogen-doped carbon nanodots prepared from polyethylenimine for fluorometric determination of salivary uric acid. Microchim Acta 2019;186:166.

[6] Xu D, Lin QL, Chang HT. Recent advances and sensing applications of carbon dots. Small Methods 2019:1900387.

[7] Li H, Yan X, Kong D, Jin R, Sun C, Du D, et al. Recent advances in carbon dots for bioimaging applications. Nanoscale Horiz 2020;5:218-34.

[8] Li H, Kang Z, Liu Y, Lee ST. Carbon nanodots: synthesis, properties and applications. J Mater Chem 2012;22: 24230-53.

[9] Zhang Z, Zhang J, Chen N, Qu L. Graphene quantum dots: an emerging material for energy-related applications and beyond. Energy Environ Sci 2012;5:8869-90.

[10] Liu J, Liu Y, Liu N, Han Y, Zhang X, Huang H, et al. Metalfree efficient photocatalyst for stable visible water splitting via a two-electron pathway. Science 2015;347:970-4.
[11] Zhuo S, Shao M, Lee ST. Upconversion and downconversion fluorescent graphene quantum dots: ultrasonic preparation and photocatalysis. ACS Nano 2012;6:1059-64.

[12] Li Y, Sun D, Liu W, Zhang M, Zhao M, Liao X, et al Modeling and simulation for microscopic traffic flow based on multiple headway, velocity and acceleration difference. Nonlinear Dyn 2011;66:15-28.

[13] Li Q, Zhang S, Dai L, Li LS. Nitrogen-doped colloidal graphene quantum dots and their size-dependent electrocatalytic activity for the oxygen reduction reaction. J Am Chem Soc 2012;134:18932-5.

[14] Jin H, Huang H, He Y, Feng X, Wang S, Dai L, et al. Graphene quantum dots supported by graphene nanoribbons with ultrahigh electrocatalytic performance for oxygen reduction. J Am Chem Soc 2015;137:7588-91.

[15] Atchudan R, Edison TNJI, Perumal S, Clament Sagaya Selvam N, Lee YR. Green synthesized multiple fluorescent nitrogen-doped carbon quantum dots as an efficient labelfree optical nanoprobe for in vivo live-cell imaging. J Photochem Photobiol A Chem 2019;372:99-107.

[16] Matea CT, Mocan T, Tabaran F, Pop T, Mosteanu O, Puia C, et al. Quantum dots in imaging, drug delivery and sensor applications. Int J Nanomedicine 2017;12:5421-31.

[17] Wang H, Li X, Tse BWC, Yang H, Thorling CA, Liu Y, et al. Indocyanine green-incorporating nanoparticles for cancer theranostics. Theranostics 2018;8:1227-42.

[18] Jian HJ, Yu J, Li YJ, Unnikrishnan B, Huang YF, Luo LJ, et al. Highly adhesive carbon quantum dots from biogenic amines for prevention of biofilm formation. Chem Eng J 2020;386:123913.

[19] Edison TNJI, Atchudan R, Shim JJ, Kalimuthu S, Ahn BC, Lee YR. Turn-off fluorescence sensor for the detection of ferric ion in water using green synthesized $\mathrm{N}$-doped carbon dots and its bio-imaging. J Photochem Photobiol B Biol 2016;158:235-42.

[20] Huang H, Lovell JF. Advanced functional nanomaterials for theranostics. Adv Funct Mater 2017;27:1603524.

[21] Kumawat MK, Thakur M, Bahadur R, Kaku T, Prabhuraj RS, Ninawe A, et al. Preparation of graphene oxide-graphene quantum dots hybrid and its application in cancer Theranostics. Mater Sci Eng C 2019;103:109774.

[22] Kojima R, Aubel D, Fussenegger M. Novel theranostic agents for next-generation personalized medicine: small molecules, nanoparticles, and engineered mammalian cells. Curr Opin Chem Biol 2015;28:29-38.

[23] Zhang RR, Swanson KI, Hall LT, Weichert JP, Kuo JS. Diapeutic cancer-targeting alkylphosphocholine analogs may advance management of brain malignancies. CNS Oncol 2016;5:223-31.

[24] Lim EK, Kim T, Paik S, Haam S, Huh YM, Lee K. Nanomaterials for theranostics: recent advances and future challenges. Chem Rev 2015;115:327-94.

[25] Lammers T, Rizzo LY, Storm G, Kiessling F. Personalized nanomedicine. Clin Cancer Res 2012;18:4889-94.

[26] Huang HT, Lin HJ, Huang HJ, Huang CC, Lin JHY, Chen LL. Synthesis and evaluation of polyamine carbon quantum dots (CQDs) in Litopenaeus vannamei as a therapeutic agent against WSSV. Sci Rep 2020;10:7343.

[27] Vats S. Methods for extractions of value-added nutraceuticals from lignocellulosic wastes and their health application. In: Ingredients Extraction by Pysicochemical Methods in Food; 2017. p. 1-64.

[28] Hsu PC, Chang HT. Synthesis of high-quality carbon nanodots from hydrophilic compounds: role of functional groups. Chem Commun 2012;8:3984-6.

[29] Wang R, Lu KQ, Tang ZR. Xu YJ Recent progress in carbon quantum dots: synthesis, properties and applications in photocatalysis. J Mater Chem A 2017;5:3717-34.

[30] De B, Karak N. A green and facile approach for the synthesis of water soluble fluorescent carbon dots from banana juice. RSC Adv 2013;3:8286-90.

[31] Yang HY, Liu YL, Guo ZY, Lei BF, Zhuang JL, Zhang XJ, et al. Hydrophobic carbon dots with blue dispersed 
emission and red aggregation-induced emission. Nat Commun 2019;10:1789.

[32] Liu S, Tian J, Wang L, Zhang Y, Qin X, Luo Y, et al. Hydrothermal treatment of grass: a low-cost, green route to nitrogen-doped, carbon-rich, photoluminescent polymer nanodots as an effective fluorescent sensing platform for label-free detection of $\mathrm{Cu}(\mathrm{II})$ ions. Adv Mater 2012;24: 2037-41.

[33] Sahu S, Behera B, Maiti TK, Mohapatra S. Simple one-step synthesis of highly luminescent carbon dots from orange juice: application as excellent bio-imaging agents. Chem Commun 2012;48:8835-7.

[34] Qiao ZA, Wang Y, Gao Y, Li H, Dai T, Liu Y, et al. Commercially activated carbon as the source for producing multicolor photoluminescent carbon dots by chemical oxidation. Chem Commun 2010;46:8812-4.

[35] Li H, He X, Kang Z, Huang H, Liu Y, Liu J, et al. Watersoluble fluorescent carbon quantum dots and photocatalyst design. Angew Chem Int Ed 2010;49:4430-4.

[36] Peng J, Gao W, Gupta BK, Liu Z, Romero-Aburto R, Ge L, et al. Graphene quantum dots derived from carbon fibers. Nano Lett 2012;12:844-9.

[37] Kushwaha N, Mittal J, Pandey S, Kumar R. High temperature acidic oxidation of multiwalled carbon nanotubes and synthesis of graphene quantum dots. Int J Nano Dimens 2018;9:191-7.

[38] Shinde DB, Pillai VK. Electrochemical preparation of luminescent graphene quantum dots from multiwalled carbon nanotubes. Chem Eur 2012;8:12522-8.

[39] Wang CC, Lu SY. Carbon black-derived graphene quantum dots composited with carbon aerogel as a highly efficient and stable reduction catalyst for the iodide/tri-iodide couple. Nanoscale 2015;7:1209-15.

[40] Liu H, Ye T, Mao C. Fluorescent carbon nanoparticles derived from candle soot. Angew Chem Int Ed 2007;46: 6473-5.

[41] Lu J, Yang JX, Wang J, Lim A, Wang S, Loh KP. One-pot synthesis of fluorescent carbon nanoribbons, nanoparticles, and graphene by the exfoliation of graphite in ionic liquids. ACS Nano 2009;3:2367-75.

[42] Zheng L, Chi Y, Dong Y, Lin J, Wang B. Electrochemiluminescence of water-soluble carbon nanocrystals released electrochemically from graphite. J Am Chem Soc 2009;31:4564-5.

[43] Sun YP, Zhou B, Lin Y, Wang W, Fernando KAS, Pathak P, et al. Quantum-sized carbon dots for bright and colorful photoluminescence. J Am Chem Soc 2006;28:7756-7.

[44] Bottini M, Balasubramanian C, Dawson MI, Bergamaschi A, Bellucci S, Mustelin T. Isolation and characterization of fluorescent nanoparticles from pristine and oxidized electric arc-produced single-walled carbon nanotubes. J Phys Chem B 2006;110:831-6.

[45] Zhu S, Zhang J, Qiao C, Tang S, Li Y, Yuan W, et al. Strongly green-photoluminescent graphene quantum dots for bioimaging applications. Chem Commun 2011;47: 6858-60.

[46] Pan D, Zhang J, Li Z, Wu M. Hydrothermal route for cutting graphene sheets into blue-luminescent graphene quantum dots. Adv Mater 2010;22:734-8.

[47] Yang ZC, Wang M, Yong AM, Wong SY, Zhang XH, Tan H, et al. Intrinsically fluorescent carbon dots with tunable emission derived from hydrothermal treatment of glucose in the presence of monopotassium phosphate. Chem Commun 2011;7:11615-7.

[48] Sharma A, Das J. Small molecules derived carbon dots: synthesis and applications in sensing, catalysis, imaging, and biomedicine. J Nanobiotechnology 2019;7:1-24.

[49] Zhang J, Yu SH. Carbon dots: large-scale synthesis, sensing and bioimaging. Mater Today 2016;19:382-93.

[50] Xie YD, Cheng DD, Liu XL, Han AX. Green hydrothermal synthesis of $\mathrm{N}$-doped carbon dots from biomass highland barley for the detection of $\mathrm{Hg}^{2+}$. Sensors (Basel) 2019;19: 3169.
[51] Zhu H, Wang X, Li Y, Wang Z, Yang F, Yang X. Microwave synthesis of fluorescent carbon nanoparticles with electrochemiluminescence properties. Chem Commun 2009;34: 5118-20.

[52] Bourlinos AB, Stassinopoulos A, Anglos D, Zboril R, Karakassides M, Giannelis EP. Surface functionalized carbogenic quantum dots. Small 2008;4:455-8.

[53] Peng H, Travas-Sejdic J. Simple aqueous solution route to luminescent carbogenic dots from carbohydrates. Chem Mater 2009;21:5563-5.

[54] Zong J, Zhu Y, Yang X, Shen J, Li C. Synthesis of photoluminescent carbogenic dots using mesoporous silica spheres as nanoreactors. Chem Commun 2011;47:764-6.

[55] Tang L, Ji R, Cao X, Lin J, Jiang H, Li X, et al. Deep ultraviolet photoluminescence of water-soluble self-passivated graphene quantum dots. ACS Nano 2012;6:5102-10.

[56] Wang J, Wang CF, Chen S. Amphiphilic egg-derived carbon dots: rapid plasma fabrication, pyrolysis process, and multicolor printing patterns. Angew Chem Int Ed 2012;51: 9297-301.

[57] Zhu S, Song Y, Zhao X, Shao J, Zhang J, Yang B. The photoluminescence mechanism in carbon dots (graphene quantum dots, carbon nanodots, and polymer dots): current state and future perspective. Nano Res 2015;8:355-81.

[58] Zhu S, Meng Q, Wang L, Zhang J, Song Y, Jin H, et al. Highly photoluminescent carbon dots for multicolor patterning, sensors, and bioimaging. Angew Chem Int Ed 2013;52:3953-7.

[59] Miao SH, Liang K, Zhu JJ, Yang B, Zhao DY, Kong B. Hetero-atom-doped carbon dots: doping strategies, properties and applications. Nano Today 2020;33:100879.

[60] Yang GC, Wu CL, Luo XJ, Liu XY, Gao Y, Wu P, et al. Exploring the emissive states of heteroatom-doped graphene quantum dots. J Phys Chem C 2018;122:6483-92.

[61] Qiao F, Wang J, Ai S, Li L. As a new peroxidase mimetics: the synthesis of selenium doped graphitic carbon nitride nanosheets and applications on colorimetric detection of $\mathrm{H}_{2} \mathrm{O}_{2}$ and xanthine. Sens Actuators B Chem 2015;216: 418-27.

[62] Li F, Yang DY, Xu HP. Non-metal-heteroatom-doped carbon dots: synthesis and properties. Chemistry 2019;25: 1165-76.

[63] Kandasamy G. Recent advancements in doped/co-doped carbon quantum dots for multi-potential applications. C 2019;5:24.

[64] Bourlinos AB, Trivizas G, Karakassides MA, Baikousi M, Kouloumpis A, Gournis D, et al. Green and simple route toward boron doped carbon dots with significantly enhanced non-linear optical properties. Carbon 2015;83: 173-9.

[65] Gong N, Wang H, Li S, Deng Y, Chen X, Ye L, Gu W. Microwave-assisted polyol synthesis of gadolinium-doped green luminescent carbon dots as a bimodal nanoprobe. Langmuir 2014;30:10933-9.

[66] Li H, Shao FQ, Huang H, Feng JJ, Wang AJ. Eco-friendly and rapid microwave synthesis of green fluorescent graphitic carbon nitride quantum dots for vitro bioimaging. Sens Actuators B Chem 2016;226:506-11.

[67] Pirsaheb M, Mohammadi S, Salimi A, Payandeh M. Functionalized fluorescent carbon nanostructures for targeted imaging of cancer cells: a review. Microchim Acta 2019;186: 231.

[68] Zuo P, Lu X, Sun Z, Guo Y, He H. A review on syntheses, properties, characterization and bioanalytical applications of fluorescent carbon dots. Microchim Acta 2016;183: 519-42.

[69] Yoo D, Park Y, Cheon B, Park MH. Carbon dots as an effective fluorescent sensing platform for metal ion detection. Nanoscale Res Lett 2019;14:272.

[70] Hettiarachchi SD, Graham RM, Mintz KJ, Zhou YQ Vanni S, Peng Z, et al. Triple conjugated carbon dots as a nano-drug delivery model for glioblastoma brain tumors. Nanoscale 2019;11:6192-205. 
[71] Sakdaronnarong C, Sangjan A, Boonsith S, Kim DC, Shin HS. Recent developments in synthesis and photocatalytic applications of carbon dots. Catalysts 2020;10:320.

[72] Manioudakis J, Victoria F, Thompson CA, Brown L, Movsum M, Lucifero R, et al. Effects of nitrogen-doping on the photophysical properties of carbon dots. J Mater Chem C 2019;7:853-62.

[73] Liu W, Zhang R, Kang Y, Zhang XY, Wang HJ, Li LH, et al. Preparation of nitrogen-doped carbon dots with a high fluorescence quantum yield for the highly sensitive detection of $\mathrm{Cu}^{2+}$ ions, drawing anti-counterfeit patterns and imaging live cells. New Carbon Mater 2019;34:390-402.

[74] Lei D, Yang W, Gong Y, Jing J, Nie H, Yu B, et al. Noncovalent decoration of carbon dots with folic acid via a polymer-assisted strategy for fast and targeted cancer cell fluorescence imaging. Sens Actuators B Chem 2016;230: 714-20.

[75] Wang J, Liu J. PEI-folic acid modified carbon nanodots for cancer cell-targeted delivery and two-photon excitation imaging. RSC Adv 2016;6:19662-8.

[76] Gao N, Yang W, Nie H, Gong Y, Jing J, Gao L, et al. Turn-on theranostic fluorescent nanoprobe by electrostatic self-assembly of carbon dots with doxorubicin for targeted cancer cell imaging, in vivo hyaluronidase analysis, and targeted drug delivery. Biosens Bioelectron 2017;96:300-7.

[77] Aiyer S, Prasad R, Kumar M, Nirvikar K, Jain B, Kushwaha OS. Fluorescent carbon nanodots for targeted in vitro cancer cell imaging. Appl Mater Today 2016;4:71-7.

[78] Liu C, Zhang P, Zhai X, Tian F, Li W, Yang J, et al. Nanocarrier for gene delivery and bioimaging based on carbon dots with PEI-passivation enhanced fluorescence. Biomaterials 2012;33:3604-13.

[79] Li Q, Ohulchanskyy TY, Liu R, Koynov K, Wu D, Best A, et al. Photoluminescent carbon dots as biocompatible nanoprobes for targeting cancer cells in vitro. J Phys Chem C 2010;114:12062-8.

[80] Su H, Liao Y, Wu F, Sun X, Liu H, Wang K, et al. Cetuximab-conjugated iodine doped carbon dots as a dual fluorescent/CT probe for targeted imaging of lung cancer cells. Colloids Surf. B Biointerfaces 2018;170:194-200.

[81] Wang C, Xu Z, Lin H, Huang Y, Zhang C. Large scale synthesis of highly stable fluorescent carbon dots using silica spheres as carriers for targeted bioimaging of cancer cells. Part Part Syst Charact 2015;32:944-51.

[82] Song Y, Shi W, Chen W, Li X, Ma H. Fluorescent carbon nanodots conjugated with folic acid for distinguishing folate-receptor-positive cancer cells from normal cells. J Mater Chem 2012;22:12568-73.

[83] Nguyen HA, Srivastava I, Pan D, Gruebele M. Unraveling the fluorescence mechanism of carbon dots with sub-single-particle resolution. ACS Nano 2020;14:6127-37.

[84] Su Y, Zhang M, Zhou N, Shao M, Chi C, Yuan P, et al. Preparation of fluorescent N, P-doped carbon dots derived from adenosine 5'-monophosphate for use in multicolor bioimaging of adenocarcinomic human alveolar basal epithelial cells. Microchim Acta 2017;184:699-706.

[85] Miao P, Han K, Tang Y, Wang B, Lin T, Cheng W. Recent advances in carbon nanodots: synthesis, properties and biomedical applications. Nanoscale 2015;7:1586-95.

[86] Qu S, Wang X, Lu Q, Liu X, Wang L. A biocompatible fluorescent ink based on water-soluble luminescent carbon nanodots. Angew Chemie Int Ed 2012;51:12215-8.

[87] Qu D, Zheng M, Du P, Zhou Y, Zhang L, Li D, et al. Highly luminescent $\mathrm{S}, \mathrm{N}$ co-doped graphene quantum dots with broad visible absorption bands for visible light photocatalysts. Nanoscale 2013;5:12272-7.

[88] Wang CI, Wu WC, Periasamy AP, Chang HT. Electrochemical synthesis of photoluminescent carbon nanodots from glycine for highly sensitive detection of hemoglobin. Green Chem 2014;16:2509-14.

[89] Kasprzyk W, Świergosz T, Bednarz S, Walas K, Bashmakova NV, Bogdał D. Luminescence phenomena of carbon dots derived from citric acid and urea-a molecular insight. Nanoscale 2018;10:13889-94.

[90] Uriarte D, Domini C, Garrido M. New carbon dots based on glycerol and urea and its application in the determination of tetracycline in urine samples. Talanta 2019;201:143-8.

[91] Hill S, Galan MC. Fluorescent carbon dots from mono- and polysaccharides: synthesis, properties and applications. Beilstein J Org Chem 2017;13:675-93.

[92] Chan KK, Yap SHK, Yong KT. Biogreen synthesis of carbon dots for biotechnology and nanomedicine applications. Nano-Micro Letters 2018;10:72.

[93] Dong Y, Chen C, Zheng X, Gao L, Cui Z, Yang H, et al. Onestep and high yield simultaneous preparation of single- and multi-layer graphene quantum dots from CX-72 Carbon Black. J Mater Chem 2012;22:8764-6.

[94] Zhang M, Bai L, Shang W, Xie W, Ma H, Fu Y, et al. Facile synthesis of water-soluble, highly fluorescent graphene quantum dots as a robust biological label for stem cells. J Mater Chem 2012;22:7461-7.

[95] Lin L, Zhang S. Creating high yield water soluble luminescent graphene quantum dots via exfoliating and disintegrating carbon nanotubes and graphite flakes. Chem Commun 2012;48:10177-9.

[96] Tang J, Zhang J, Xiao YM, Shi YL, Chen YH, Ding L, Xu W. Influence of group modification at the edges of carbon quantum dots on fluorescent emission. Nanoscale Res Lett 2019;14:241.

[97] Sciortino A, Marino E, Van Dam B, Schall P, Cannas M, Messina F. Solvatochromism Unravels the Emission Mechanism of Carbon Nanodots. J Phys Chem Lett 2016;7: 3419-23.

[98] Khan S, Gupta A, Verma NC, Nandi CK. Time-Resolved Emission Reveals Ensemble of Emissive States as the Origin of Multicolor Fluorescence in Carbon Dots. Nano Lett 2015; 15:8300-5.

[99] Miao X, Qu D, Yang D, Nie B, Zhao Y, Fan H, et al. Synthesis of Carbon Dots with Multiple Color Emission by Controlled Graphitization and Surface Functionalization. Adv Mater 2018;30.

[100] Nguyen HA, Srivastava I, Pan D, Gruebele M. Unraveling the Fluorescence Mechanism of Carbon Dots with SubSingle-Particle Resolution. ACS Nano 2020;14:6127-37.

[101] Tepliakov NV, Kundelev EV, Khavlyuk PD, Xiong Y, Leonov MY, Zhu W, et al. Sp2-sp3-Hybridized Atomic Domains Determine Optical Features of Carbon Dots. ACS Nano 2019;13:10737-44.

[102] Chen Y, Zheng M, Xiao Y, Dong H, Zhang H, Zhuang J, et al. A Self-Quenching-Resistant Carbon-Dot Powder with Tunable Solid-State Fluorescence and Construction of Dual-Fluorescence Morphologies for White Light-Emission. Adv Mater 2016;28:312-8.

[103] Yuan F, Li S, Fan Z, Meng X, Fan L, Yang S. Shining carbon dots: synthesis and biomedical and optoelectronic applications. Nano Today 2016;11:565-86.

[104] Ge J, Lan M, Zhou B, Liu W, Guo L, Wang H, et al. A graphene quantum dot photodynamic therapy agent with high singlet oxygen generation. Nat Commun 2014;5:4596.

[105] Tang L, Ji R, Li X, Bai G, Liu CP, Hao J, et al. Deep ultraviolet to near-infrared emission and photoresponse in layered n-doped graphene quantum dots. ACS Nano 2014; 8:6312-20.

[106] Jiang K, Sun S, Zhang L, Lu Y, Wu A, Cai C, et al. Red, green, and blue luminescence by carbon dots: full-color emission tuning and multicolor cellular imaging. Angew Chem Int Ed Engl 2015;54:5360-3.

[107] Pan L, Sun S, Zhang A, Jiang K, Zhang L, Dong C, et al. Truly fluorescent excitation-dependent carbon dots and their applications in multicolor cellular imaging and multidimensional sensing. Adv Mater 2015;27:7782-7.

[108] Zhang Y, He J. Facile synthesis of S, N co-doped carbon dots and investigation of their photoluminescence properties. Phys Chem Chem Phys 2015;17:20154-9. 
[109] Li X, Zhang S, Kulinich SA, Liu Y, Zeng H. Engineering surface states of carbon dots to achieve controllable luminescence for solid-luminescent composites and sensitive $\mathrm{Be}^{2+}$ detection. Sci Rep 2014;4:4976.

[110] Lesani P, Singh G, Viray CM, Ramaswamy Y, Zhu DM, Kingshott $\mathrm{P}$, et al. Two-photon dual-emissive carbon dotbased probe: deep-tissue imaging and ultrasensitive sensing of intracellular ferric ions. ACS Appl Mater Interfaces 2020;12:18395-406.

[111] Liu Q, Guo B, Rao Z, Zhang B, Gong JR. Strong two-photoninduced fluorescence from photostable, biocompatible nitrogen-doped graphene quantum dots for cellular and deep-tissue imaging. Nano Lett 2013;13:2436-41.

[112] Tang J, Kong B, Wu H, Xu M, Wang Y, Wang Y, et al. Carbon nanodots featuring efficient FRET for real-time monitoring of drug delivery and two-photon imaging. Adv Mater 2013;25:6569-74.

[113] Kim J, Song SH, Jin YH, Park HJ, Yoon HW, Jeon SK, et al. Multiphoton luminescent graphene quantum dots for in vivo tracking of human adipose-derived stem cells. Nanoscale 2016;8:8512-9.

[114] Salinas-Castillo A, Ariza-Avidad M, Pritz C, CamprubíRobles M, Fernández B, Rama MJR, et al. Carbon dots for copper detection with down and upconversion fluorescent properties as excitation sources. Chem Commun 2013;49: 1103-5.

[115] Shen J, Zhu Y, Chen C, Yang X, Li C. Facile preparation and upconversion luminescence of graphene quantum dots. Chem Commun 2011;47:2580-2.

[116] Zhu S, Zhang J, Tang S, Qiao C, Wang L, Wang H, et al. Surface chemistry routes to modulate the photoluminescence of graphene quantum dots: from fluorescence mechanism to up-conversion bioimaging applications. Adv Funct Mater 2012;22:4732-40.

[117] Gan Z, Wu X, Zhou G, Shen J, Chu PK. Is there real upconversion photoluminescence from graphene quantum dots? Adv Opt Mater 2013;1:554-8.

[118] Zahra F, Neda E, Hamide E, Zeinab B, Hossein T, Zahra R, et al. Physicochemical and cytotoxicity analysis of green synthesis carbon dots for cell imaging. EXCLI J 2019;18: 454-66.

[119] Du JJ, Xu N, Fan J, Sun W, Peng X. Carbon dots for in vivo bioimaging and theranostics. Small 2019;15:1805087.

[120] Unnikrishnan B, Wu RS, Wei SC, Huang CC, Chang HT. Fluorescent Carbon Dots for Selective Labeling of Subcellular Organelles 2020;5. 2020. p. 11248-61.

[121] Mishra V, Patil A, Thakur S, Kesharwani P. Carbon dots: emerging theranostic nanoarchitectures. Drug Discov Today 2018;23:1219-32.

[122] Lai IPJ, Harroun SG, Chen SY, Unnikrishnan B, Li YJ, Huang CC. Solid-state synthesis of self-functional carbon quantum dots for detection of bacteria and tumor cells. Sens Actuators B Chem 2016;228:465-70.

[123] Pan D, Guo L, Zhang J, Xi C, Xue Q, Huang H, et al. Cutting $\mathrm{sp} 2$ clusters in graphene sheets into colloidal graphene quantum dots with strong green fluorescence. J Mater Chem 2012;22:3314-8.

[124] Hu C, Liu Y, Yang Y, Cui J, Huang Z, Wang Y, et al. Onestep preparation of nitrogen-doped graphene quantum dots from oxidized debris of graphene oxide. J Mater Chem B 2013;1:39-42.

[125] Ge J, Jia Q, Liu W, Guo L, Liu Q, Lan M, et al. Red-emissive carbon dots for fluorescent, photoacoustic, and thermal theranostics in living mice. Adv Mater 2015;27:4169-77.

[126] Biju V, Itoh T, Ishikawa M. Delivering quantum dots to cells: bioconjugated quantum dots for targeted and nonspecific extracellular and intracellular imaging. Chem Soc Rev 2010;9:3031-56.

[127] Du FY, Li JN, Hua Y, Zhang MM, Zhou Z, Yuan J, et al. Multicolor nitrogen-doped carbon dots for live cell imaging. J Biomed Nanotechnol 2015;11:780-8.

[128] Horobin RW, Stockert JC, Rashid-Doubell F. Uptake and localisation of small-molecule fluorescent probes in living cells: a critical appraisal of QSAR models and a case study concerning probes for DNA and RNA. Histochem Cell Biol 2013;139:623-37.

[129] Liu HF, Yang J, Li ZH, Xiao LH, Aryee AA, Sun YQ, et al. Hydrogen-bond-induced emission of carbon dots for washfree nucleus imaging. Anal Chem 2019;91:9259-65.

[130] Datta KKR, Kozák O, Ranc V, Havrdová M, Bourlinos AB, Šafářová $K$, et al. Quaternized carbon dot-modified graphene oxide for selective cell labelling - controlled nucleus and cytoplasm imaging. Chem Commun 2014;50:10782-5.

[131] Kang YF, Fang YW, Li YH, Li W, Yin XB. Nucleus-staining with biomolecule-mimicking nitrogen-doped carbon dots prepared by a fast neutralization heat strategy. Chem Commun 2015;51:16956-9.

[132] Hua XW, Bao YW, Zeng J, Wu FG. Nucleolus-Targeted Red Emissive Carbon Dots with Polarity-Sensitive and Excitation-Independent Fluorescence Emission: High-Resolution Cell Imaging and in Vivo Tracking. ACS Appl Mater Interfaces 2019;11:32647-58.

[133] Hua XW, Bao YW, Wu FG. Fluorescent Carbon Quantum Dots with Intrinsic Nucleolus-Targeting Capability for Nucleolus Imaging and Enhanced Cytosolic and Nuclear Drug Delivery. ACS Appl Mater Interfaces 2018;10: 10664-77.

[134] Gao G, Jiang YW, Yang J, Wu FG. Mitochondria-targetable carbon quantum dots for differentiating cancerous cells from normal cells. Nanoscale 2017;9:18368-78.

[135] Ran HH, Cheng X, Bao YW, Hua XW, Gao G, Zhang X, et al. Multifunctional quaternized carbon dots with enhanced biofilm penetration and eradication efficiencies. J Mater Chem B 2019;7:5104-14.

[136] Gao G, Jiang YW, Jia HR, Yang J, Wu FG. On-off-on fluorescent nanosensor for $\mathrm{Fe} 3+$ detection and cancer/normal cell differentiation via silicon-doped carbon quantum dots. Carbon N Y 2018;134:232-43.

[137] Cao L, Wang X, Meziani MJ, Lu F, Wang H, Luo PG, et al. Carbon dots for multiphoton bioimaging. J Am Chem Soc 2007;129:11318-9.

[138] Kong B, Zhu A, Ding C, Zhao X, Li B, Tian Y. Carbon dotbased inorganic-organic nanosystem for two-photon imaging and biosensing of $\mathrm{pH}$ variation in living cells and tissues. Adv Mater 2012;24:5844-8.

[139] Roy P, Periasamy AP, Lin CY, Her GM, Chiu WJ, Li CL, et al. Photoluminescent graphene quantum dots for in vivo imaging of apoptotic cells. Nanoscale 2015;7:2504-10.

[140] Wu X, Tian F, Wang W, Chen J, Wu M, Zhao JX. Fabrication of highly fluorescent graphene quantum dots using L-glutamic acid for in vitro/in vivo imaging and sensing. J Mater Chem C 2013;1:f14476-84.

[141] Qian Z, Shan X, Chai L, Ma J, Chen J, Feng H. Si-doped carbon quantum dots: a facile and general preparation strategy, bioimaging application, and multifunctional sensor. ACS Appl Mater Interfaces 2014;6:6797-805.

[142] Shan X, Chai L, Ma J, Qian Z, Chen J, Feng H. B-doped carbon quantum dots as a sensitive fluorescence probe for hydrogen peroxide and glucose detection. Analyst 2014;139: 2322-5.

[143] Chen Z, Wang J, Miao H, Wang L, Wu S, Yang X. Fluorescent carbon dots derived from lactose for assaying folic acid. Sci China Chem 2016;59:487-92.

[144] Yang J, He X, Chen L, Zhang Y. The selective detection of galactose based on boronic acid functionalized fluorescent carbon dots. Anal Methods 2016;8:8345-51.

[145] Lan J, Liu C, Gao M, Huang C. An efficient solid-state synthesis of fluorescent surface carboxylated carbon Dots derived from $\mathrm{C} 60$ as a label-free probe for iron ions in living cells. Talanta 2015:144:93-7.

[146] Zhang Y, Cui P, Zhang F, Feng X, Wang Y, Yang Y, et al. Fluorescent probes for "off-on" highly sensitive detection of $\mathrm{Hg} 2+$ and L-cysteine based on nitrogen-doped carbon dots. Talanta 2016;152:288-300.

[147] Li Z, Yu H, Bian T, Zhao Y, Zhou C, Shang L, et al. Highly luminescent nitrogen-doped carbon quantum dots as 
effective fluorescent probes for mercuric and iodide ions. J Mater Chem C 2015;3:1922-8.

[148] Ghanem A, Al-Marjeh RAQ, Atassi Y. Novel nitrogendoped carbon dots prepared under microwave-irradiation for highly sensitive detection of mercury ions. Heliyon 2020; 6:e03750.

[149] Xu Q, Su R, Chen Y, Sreenivasan ST, Li N, Zheng X, et al. Metal charge transfer doped carbon dots with reversibly switchable, ultra-high quantum yield photoluminescence. ACS Appl Nano Mater 2018;1:1886-93.

[150] Wang BB, Jin JC, Xu ZQ, Jiang ZW, Li X, Jiang FL, et al. Single-step synthesis of highly photoluminescent carbon dots for rapid detection of $\mathrm{Hg}^{2+}$ with excellent sensitivity. J Colloid Interface Sci 2019;551:101-10.

[151] Li B, Ma H, Zhang B, Qian J, Cao T, Feng H, et al. Dually emitting carbon dots as fluorescent probes for ratiometric fluorescent sensing of $\mathrm{pH}$ values, mercury(II), chloride and $\mathrm{Cr}(\mathrm{VI})$ via different mechanisms. Microchim Acta 2019;186: 341.

[152] Ren G, Zhang Q, Li S, Fu S, Chai F, Wang C, et al. One pot synthesis of highly fluorescent $\mathrm{N}$ doped c-dots and used as fluorescent probe detection for $\mathrm{Hg}^{2+}$ and $\mathrm{Ag}^{+}$in aqueous solution. Sens Actuators B Chem 2017;243:244-53.

[153] Qian Z, Ma J, Shan X, Feng H, Shao L, Chen J. Highly luminescent $\mathrm{N}$-doped carbon quantum dts as an effective multifunctional fluorescence sensing platform. Chem Eur J 2014;20:2254-63.

[154] Li J, Zuo G, Pan X, Wei W, Qi X, Su T, et al. Nitrogen-doped carbon dots as a fluorescent probe for the highly sensitive detection of $\mathrm{Ag}+$ and cell imaging. Luminescence 2018;33: 243-8.

[155] Wang F, Lu Y, Chen Y, Sun J, Liu Y. Colorimetric nanosensor based on the aggregation of AuNP triggered by carbon quantum dots for detection of $\mathrm{Ag}^{+}$ions. ACS Sustain Chem Eng 2018;6:3706-13.

[156] Qin J, Zhang LM, Yang R. Powder carbonization to synthesize novel carbon dots derived from uric acid for the detection of $\operatorname{Ag}(\mathrm{I})$ and glutathione. Spectrochim Acta A Mol Biomol Spectrosc 2019;207:54-60.

[157] Qin Z, Wang W, Zhan X, Du X, Zhang Q, Zhang R, et al. One-pot synthesis of dual carbon dots using only an $\mathrm{N}$ and $\mathrm{S}$ co-existed dopant for fluorescence detection of $\mathrm{Ag}+$. Spectrochim Acta A Mol Biomol Spectrosc 2019;208:162-71.

[158] Huang SW, Lin YF, Li YX, Hu CC, Chiu TC. Synthesis of fluorescent carbon dots as selective and sensitive probes for cupric ions and cell imaging. Molecules 2019;24:1785.

[159] Wu J, Feng Y, Shao Y, Sun Y. High quality nitrogen and silicon co-doped carbon dots (N/Si-CDs) for Fe3+ sensing. J Nanosci Nanotechnol 2017;18:4196-203.

[160] Sun Y, Wang X, Wang C, Tong D, Wu Q, Jiang K, Jiang Y, Wang C, Yang M. Red emitting and highly stable carbon dots with dual response to $\mathrm{pH}$ values and ferric ions. Microchim Acta 2018;185:83.

[161] Hu S, Zhao Q, Chang Q, Yang J, Liu J. Enhanced performance of $\mathrm{Fe}^{3+}$ detection via fluorescence resonance energy transfer between carbon quantum dots and rhodamine $B$. RSC Adv 2014;4:41069-75.

[162] Chandra S, Chowdhuri AR, Laha D, Sahu SK. Fabrication of nitrogen- and phosphorous-doped carbon dots by the pyrolysis method for iodide and iron(III) sensing. Luminescence 2018;33:336-44.

[163] Zhang J, Yan J, Wang Y, Zhang Y. One-step hydrothermal approach to synthesis carbon dots from D-sorbitol for detection of iron(III) and cell imaging. J Nanosci Nanotechnol 2017;18:4457-63.

[164] Zhou L, Lin Y, Huang Z, Ren J, Qu X. Carbon nanodots as fluorescence probes for rapid, sensitive, and label-free detection of $\mathrm{Hg}^{2+}$ and biothiols in complex matrices. Chem Commun 2012;48:1147-9.

[165] Guo Y, Wang Z, Shao H, Jiang X. Hydrothermal synthesis of highly fluorescent carbon nanoparticles from sodium citrate and their use for the detection of mercury ions. Carbon 2013;52:583-9.
[166] Lin YS, Lin YL, Periasamy AP, Cang JS, Chang HT. Parameters affecting the synthesis of carbon dots for quantitation of copper ions. Nanoscale Adv 2019;1:2553-61.

[167] Yen YT, Lin YS, Chen TY, Chyueh SC, Chang HT. Carbon dots functionalized papers for high-throughput sensing of 4-chloroethcathinone and its analogues in crime sites. R Soc open sci 2019;6:191017.

[168] Yen YT, Lin YS, Chen TH, Chyueh SC, Chang HT. A carbon-dot sensing probe for screening of date rape drugs: nitro-containing benzodiazepines. Sens Actuators B Chem 2020;305:127441.

[169] Li HW, Mao JY, Lien CW, Wang CK, Lai JY, Mandal RP, et al. Platinum ions mediate the interactions between DNA and carbon quantum dots: diagnosis of MRSA infections. J Mater Chem B 2020;8:3506-12.

[170] Khan MS, Pandey S, Talib A, Bhaisare ML, Wu HF. Controlled delivery of dopamine hydrochloride using surface modified carbon dots for neuro diseases. Colloids Surf B 2015;134:140-6.

[171] Farokhzad OC, Langer R. Impact of nanotechnology on drug delivery. ACS Nano 2009;3:16-20.

[172] Li CL, Ou CM, Huang CC, Wu WC, Chen YP, Lin TE, et al. Carbon dots prepared from ginger exhibiting efficient inhibition of human hepatocellular carcinoma cells. J Mater Chem B 2014;2:4564-71.

[173] Liu Z, Chen X, Zhang X, Gooding JJ, Zhou Y. Targeted drug delivery: carbon-quantum-dots-loaded mesoporous silica nanocarriers with $\mathrm{pH}$-switchable zwitterionic surface and enzyme-responsive pore-cap for targeted imaging and drug delivery to tumor. Adv Healthc Mater 2016;5:1401-7.

[174] Feng T, Ai X, Ong H, Zhao Y. Dual-responsive carbon dots for tumor extracellular microenvironment triggered targeting and enhanced anticancer drug delivery. ACS Appl Mater Interfaces 2016;8:18732-40.

[175] Chowdhuri AR, Singh T, Ghosh SK, Sahu SK. Carbon dots embedded magnetic nanoparticles@ @ chitosan @metal organic framework as a nanoprobe for $\mathrm{pH}$ sensitive targeted anticancer drug delivery. ACS Appl Mater Interfaces 2016;8:16573-83.

[176] Peng Z, Miyanji EH, Zhou Y, Pardo J, Hettiarachchi SD, Li S, et al. Carbon dots: promising biomaterials for bonespecific imaging and drug delivery. Nanoscale 2017;9: 17533-43.

[177] Yang J, Gao G, Zhang X, Ma YH, Jia HR, Jiang YW, et al Ultrasmall and photostable nanotheranostic agents based on carbon quantum dots passivated with polyamine-containing organosilane molecules. Nanoscale 2017;9:15441-52.

[178] Du F, Zhang M, Gong A, Tan Y, Miao J, Gong Y, et al. Engineered gadolinium-doped carbon dots for magnetic resonance imaging-guided radiotherapy of tumors. Biomaterials 2017;121:109-20.

[179] Ginn SL, Alexander IE, Edelstein ML, Abedi MR, Wixon J. Gene therapy clinical trials worldwide to 2012 - an update. J Gene Med 2013;15:65-77.

[180] Vincent M, De Lázaro I, Kostarelos K. Graphene materials as $2 \mathrm{D}$ non-viral gene transfer vector platforms. Gene Ther 2017;24:123-32.

[181] Wang HJ, He X, Luo TY, Zhang J, Liu YH, Yu XQ. Amphiphilic carbon dots as versatile vectors for nucleic acid and drug delivery. Nanoscale 2017;9:5935-47.

[182] Prabhu P, Patravale V. The upcoming field of theranostic nanomedicine: an overview. J Biomed Nanotechnol 2012;8: 859-82.

[183] Zou L, Wang H, He B, Zeng L, Tan T, Cao H, et al. Current approaches of photothermal therapy in treating cancer metastasis with nanotherapeutics. Theranostics 2016;6: $762-72$.

[184] DeRosa MC, Crutchley RJ. Photosensitized singlet oxygen and its applications. Coord Chem Rev 2002;233-4:351-71.

[185] He H, Zheng X, Liu S, Zheng M, Xie Z, Wang Y, et al. Diketopyrrolopyrrole-based carbon dots for photodynamic therapy. Nanoscale 2018;10:10991-8. 
[186] Hua XW, Bao YW, Chen Z, Wu FG. Carbon quantum dots with intrinsic mitochondrial targeting ability for mitochondria-based theranostics. Nanoscale 2017;9:10948-60.

[187] Jian HJ, Wu RS, Lin TY, Li YJ, Lin HJ, Harroun SG, et al. Super-cationic carbon quantum dots synthesized from spermidine as an eye drop formulation for topical treatment of bacterial keratitis. ACS Nano 2017;11:6703-16.

[188] Lin CJ, Chang L, Chu HW, Lin HJ, Chang PC, Wang RYL, et al. High amplification of the antiviral activity of curcumin through transformation into carbon quantum dots. Small 2019;15:1902641.

[189] Yang J, Zhang X, Ma YH, Gao G, Chen X, Jia HR, et al. Carbon Dot-Based Platform for Simultaneous Bacterial Distinguishment and Antibacterial Applications. ACS Appl Mater Interfaces 2016;8:32170-81.
[190] Yang J, Gao G, Zhang X, Ma YH, Chen X, Wu FG. One-step synthesized carbon dots with bacterial contact-enhanced fluorescence emission property: Fast Gram-type identification and selective Gram-positive bacterial inactivation. Carbon N Y 2019;146:827-39.

[191] Lin F, Bao Y-W, Wu F-G. Carbon Dots for Sensing and Killing Microorganisms. C Journal of Carbon Research 2019;5:33.

[192] Chen TH, Chang HT. Stable and photoswitchable carbondot liposome. ACS Appl Mater Interfaces 2017;9:44259-63.

[193] Chang HT, Chen TH, Periasamy AP. Process for forming Janus particles and application thereof. Publication Number: 20180221291. 2018. 